\title{
Monitoring of Air Pollutants Using Plants and Co- Located Soil - Egypt: Characteristics, Pollution, and Toxicity Impact
}

\section{Wael M Badawy}

Egyptian Atomic Energy Authority

\section{Yasmin Sarhan}

Menoufia University

Octavian G Duliu

University of Bucharest: Universitatea din Bucuresti

Junbeum Kim ( $\nabla$ junbeum.kim@utt.fr)

University of Technology of Troyes https://orcid.org/0000-0003-0665-7989

\section{Nikita Yushin}

Nuclear Research Center

\section{Hussein El Samman}

Menoufia University

Abdel Azim Hussein

Menoufia University

\section{Marina Frontasyeva}

Nuclear Research Center

\section{Alexey Shcheglov}

Moscow State University: Moskovskij gosudarstvennyj universitet imeni M V Lomonosova

\section{Research Article}

Keywords: Plants biomonitoring, INAA, AAS, pollution indices, toxicity impact

Posted Date: April 7th, 2021

DOl: https://doi.org/10.21203/rs.3.rs-314815/v1

License: (c) (i) This work is licensed under a Creative Commons Attribution 4.0 International License. Read Full License 
17218-7. 


\section{Monitoring of air pollutants using plants and co-located soil - Egypt : characteristics, pollution, and toxicity impact}

Wael Badawy ${ }^{1,5^{*}}$, Yasmin Sarhan², Octavian Duliu' ${ }^{3,5}$, Junbeum Kim ${ }^{4,7^{* *}}$, Nikita

Yushin ${ }^{5}$, Hussein El Samman ${ }^{2}$, Abdel Azim Hussein², Marina Frontasyeva ${ }^{5}$,

Alexey Shcheglov ${ }^{6}$

${ }^{1}$ Radiation Protection \& Civil Defense Department, Nuclear Research Center, Egyptian Atomic Energy Authority (EAEA), 13759 Abu Zaabal, Egypt.

${ }^{2}$ Menoufia University, Faculty of Science, Department of Physics, Shibin El-koom, Egypt

${ }^{3}$ University of Bucharest, Faculty of Physics, Department of Atomic and Nuclear Physics, 405, Atomistilor str 077125 Magurele, Romania

${ }^{4}$ CREIDD Research Centre on Environmental Studies \& Sustainability, Department of Humanity, Environment \& Information Technology, the University of Technology of Troyes,

France.

${ }^{5}$ Frank Laboratory of Neutron Physics, Joint Institute for Nuclear Research, str. Joliot-Curie, 6, 141980 Dubna, Moscow Region, Russian Federation

${ }^{6}$ Faculty of Soil Science, Moscow State University, Moscow 119991, Russia

${ }^{7}$ Division for Geology of School of Earth Sciences and Engineering, National Research Tomsk Polytechnic University, Russia

\footnotetext{
* Corresponding author: wael@jinr.ru; ${ }^{* *}$ Corresponding author: junbeum.kim@utt.fr
} 


\section{Highlights}

2 - Characterization and monitoring of the air quality in terms of pollution and toxicity impact.

4

- The concentrations of 35 and 40 elements were determined using two analytical methods.

5

- Instrumental neutron activation analysis and atomic absorption spectrometer.

6

- The enrichment factor, pollution load index, potential ecological risk, risk index, and human and ecotoxicity were assessed.

8 


\section{Graphical abstract}

10

11

12

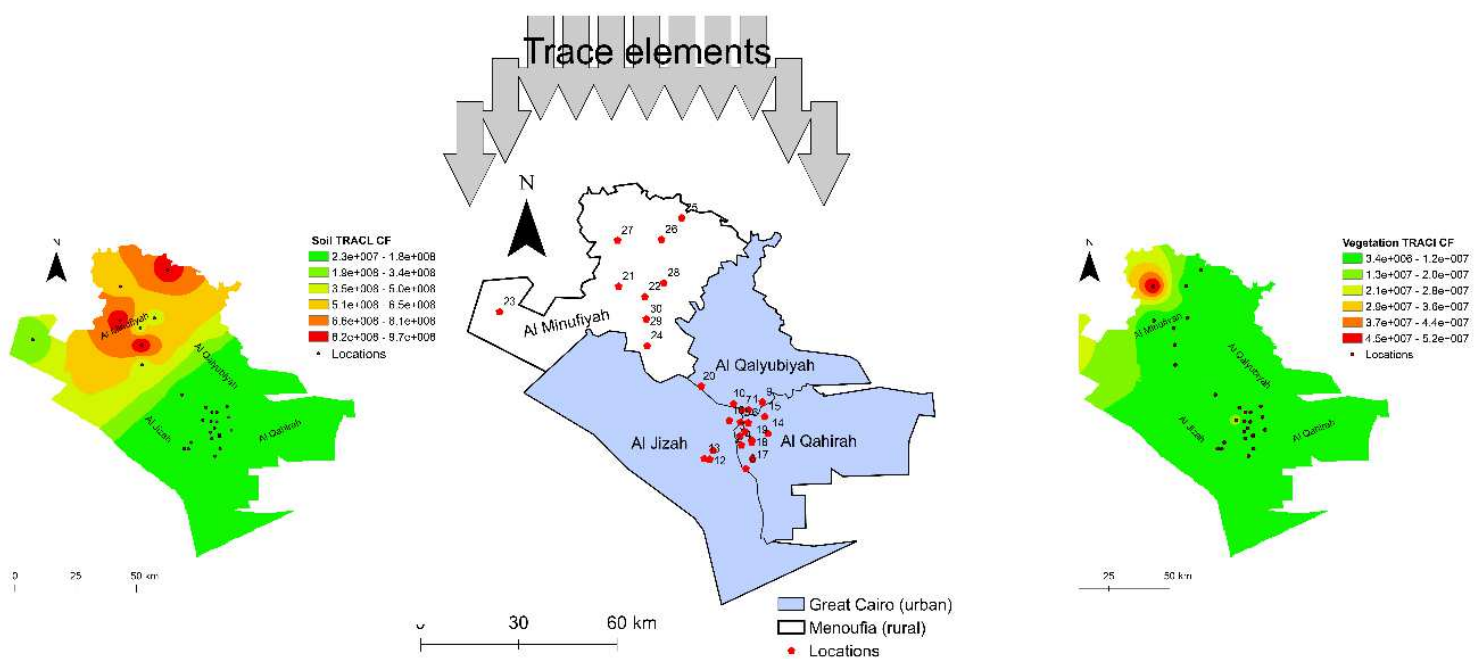

13

Human toxicity and terrestrial ecotoxicity results including soil and 


\section{Abstract:}

The present work was conducted to characterize and monitor the air quality in terms of pollution and toxicity impact using two evergreen tree leaves, Eucalyptus globulus Labill and Ficus benjamina $L$. as biomonitors. Thirty tree leaves and an equal number of co-located soil samples from different regions of Egypt (urban Greater Cairo Metropolitan GC and rural Menoufia Governorate MG) were collected. The concentrations of 34 and 40 elements were determined using instrumental neutron activation analysis and atomic absorption spectrometer. Bivariate and multivariate statistical analysis were implemented. The air pollution was assessed using enrichment factor, pollution load index, potential ecological risk, and risk index. In addition, human and ecotoxicity were evaluated based on the ReCiPe method. The mean concentration values of the obtained elements in tree leaves in urban Greater Cairo and rural Menoufia Governorate show that the major elements are slightly higher in F. benjamina than in E. globulus. Likewise, the mean values of elements in soil from Greater Cairo and Menoufia Governorate show no significant difference except for major elements (Fe, Al, Mg, K, Na, and $\mathrm{Ti}$ ) in Menoufia Governorate. The normalized concentrations of tree species and soil show that the accumulated elements by F. benjamina is slightly higher than in E. globulus in Greater Cairo GC and Menoufia Governorate MG. While in terms of the investigated area, the concentrations of elements in MG is considerably higher than in GC. PLI spatial distribution over investigated areas showed that despite high population density, heavy traffic, and urban pollution, the Cairo samples exhibit significantly lower values as compared to those from Menoufia, which is most likely due to the uncontrolled industrial and domestic waste disposal outside Cairo. PER was significant for As in Soil and for As and Cd for tree species. Human toxicity shows higher values in urban locations. Contrariwise, in the terrestrial ecotoxicity aspect, the rural locations are much higher than in urban ones.

Keywords: Plants biomonitoring; INAA; AAS; pollution indices; toxicity impact

\section{Introduction}

Air pollution becomes one of the most serious problems caused by human activities. Air pollutants are made up of a mixture of gas, liquid, and solid compounds of the air and particulate matter (PM). They may cause adverse health effects in humans and affect plant life and cause detrimental changes in the atmosphere of the earth (Brunekreef and Holgate, 2002; Kampa and Castanas, 2008; Rai, 2016). Heavy metals can easily be linked to terrestrial food webs (Gall et al., 
2015). They are steady in the environment and are dangerous in case of intake via different pathways (ingestion, inhalation, and dermal contact) by a human. The sources of pollution are dramatically increasing. For instance; processes of urbanization expansion, industrialization, and economic development (Acosta et al., 2015; Hassanien, 2011; Rai, 2016; Salim Akhter and Madany, 1993; Yekeen et al., 2016).

The quality of soil and plants is affected mainly by the growing demand for agricultural food due to population growth and urbanization (Shah et al., 2019). Heavy metals are accumulated in trees through the foliage, and it is considered the major pathway, specifically in polluted areas (Farahat, 2011). Trees are quite efficient in trapping atmospheric deposited particles. The utilization of tree leaves as biomonitors in accumulating metals has acquired great ecological and ecotoxicological importance (Farahat, 2011; Yalaltdinova et al., 2018). In the recent Anthropocene, a variety of urban and rural roadside trees is now increasingly recognized as an environmentally sustainable tool for monitoring and mitigating the effects of air pollution. The deposition of PM particulates in the foliar surface of tree leaves causes structural and functional changes in plants (Panda and Rai, 2015; Rai, 2016). Tree leaves as biomonitors are an accessible and inexpensive tool for the evaluation of atmospheric air deposition.

Some methods may also be utilized, such as moss and lichen. Because of their root system, they ultimately accumulate pollutants from the atmosphere, and the crustal association is minimal (Christensen et al., 2018; Steinnes, 1995; Steinnes et al., 1994; Steinnes et al., 1992; Steinnes et al., 2017; Vuković et al., 2016). As biomonitors and vascular plants, the main similarities and differences between moss and lichens are as follows; both of them act as good biomonitors. However, moss and lichens are mainly grown in wetland regions and barely find them in arid and hot countries like Egypt. Therefore, high plants have a root system, and tree leaves act as good biomonitors (Farahat, 2011; Gorelova and Frontasyeva, 2017; Jiang et al., 2018; Kabata-Pendias, 2011; Norouzi et al., 2015; Panda and Rai, 2015; Peterson and Girling, 1981); Quénéa et al. (2019); (Rai, 2016; Ukpebor et al., 2010). The Egyptian population is $98 \mathrm{M}$, and almost $40 \%$ is mainly inhabited in Delta Nile, according to CAPMS (2019). Greater Cairo Metropolitan consists of three main governorates are Cairo, Giza, and Kalyobia, where approximately $24 \mathrm{M}$ is inhabited, and population density is 51029, 7416, and $5356 \mathrm{pop} / \mathrm{km}^{2}$, respectively (CAPMS, 2019). Therefore, Greater Cairo Metropolitan (GC) is an overpopulated city and one of the most populated cities in the world.

Because of the expensive cost of monitoring instrumentation and difficulties in associated sampling methods, the suitability of two commons, ubiquitously distributed, and ornamental plant species in Greater Cairo (GC) and Menoufia Governorate (MG) as biomonitors and as effective bioaccumulators of atmospheric trace metals have been evaluated. Eucalyptus globulus Labill and 
Ficus benjamina L 1767 were selected as biomonitors, and the concentrations of 32 elements were determined. Both E. globulus and F. benjamina are evergreen tree species planted in the Mediterranean environment (Fife et al., 2008). E. globulus is a forest tree widely grown for woody biomass production in Mediterranean climates (Wilson, 1993). E. globulus mature leaves are narrow, sickle-shaped with a length of 8 to $12 \mathrm{~cm}$ and about $1 \mathrm{~cm}$ wide. Whereas, F. benjamina leaves are oval with 5 to $12 \mathrm{~cm}$ long and 2 to $6 \mathrm{~cm}$ wide. Therefore, these properties could influence aerial dust retention capacity. The adjacent soils were sampled and evaluated in terms of trace elements for 40 elements. Two complementary analytical methods were used in the analysis; instrumental neutron activation INAA and atomic absorption spectrometer AAS. All the elements were determined through INAA, except $\mathrm{Cu}, \mathrm{Cd}$, and $\mathrm{Pb}$ in plants only were determined using AAS.

Up to date, many important studies have paid attention to heavy metal sampling, analysis, and toxicity assessment using topsoils, biomonitors, and vascular plants. Tong et al. (2020) Tong et al. showed an overview of heavy metal pollution studies in the urban soils throughout 71 cities of China, based on data from online literature, during the period 2003-2019. The study focused on $\mathrm{As}, \mathrm{Cd}, \mathrm{Cr}, \mathrm{Hg}, \mathrm{Pb}, \mathrm{Cu}, \mathrm{Zn}$, and $\mathrm{Ni}$ heavy metals. The study also introduced and evaluated the pollution index, potential ecological risk index, and hazard index. The results show that eight heavy metals' mean values all exceeded the soil background values in China.

Morton-Bermea et al. (2009) studied an assessment of heavy metal pollution $(\mathrm{Cr}, \mathrm{Cu}, \mathrm{Ni}$, $\mathrm{Pb}, \mathrm{Zn}$, and V) in 135 urban topsoil samples from the metropolitan area of Mexico City. Using the pollution indices, the metal accumulation with respect to the background values was calculated in this study. The study showed that the assessment of heavy metal pollution in urban topsoil is an effective approach to determine the environmental damage from industry and human activities

Related with soil contamination in an urban and agricultural area, Shifaw (2018) reviewed and analyzed national scale heavy metals soil contamination in urban and agricultural areas in China. With 100 individual studies, the concentration, pollution level, sources, remedial actions, and impacts of soil heavy metals in China were investigated.

Yalaltdinova et al. (2018) studied the atmospheric inorganic pollutants and the relevant potential toxic impacts on humans and the ecosystem. In this study, the trace elements deposited from the atmosphere using Populus nigra as a bioaccumulative indicator and potential human and ecotoxicity impacts were evaluated and quantified.

El-Khatib et al. (2020) investigated the ability of Ficus nitida and Eucalyptus globulus, bark, and soil as biomonitors in some industrial zones in Minya governorate. In this research, the concentrations of $\mathrm{Pb}, \mathrm{Cu}$, and $\mathrm{Cd}$ were determined. Also, the highest concentrations were observed in tree leaves, which, in turn, suggests the implementation of tree leaves as biomonitors for metalair quality assessment. 
An up-to-date overview of information about the assessment of the inorganic metal air pollution and its impact on both human and terrestrial ecosystem by the implementation of tree

123 leaves in Egypt is presented. Although some attempts have been made to address this issue, it is still a lack of information that could give a wide-scale and comprehensive description of the investigated areas as these studies are characterized mainly by local zones and areas.

The objectives of the current investigations can be summarized as i) determination of the concentrations of trace elements in tree leaves and adjacent soils, ii) identifying of the pollution extent using different pollution indices, and finally, iii) assessment and calculation of human toxicity and terrestrial ecotoxicity from selected elements and locations, iv) extracting more information about the main sources of pollution by implementing bivariate and multivariate statistical analysis, and iv) delivering the qualitative and quantitative estimation of the metal-air pollutants in GC and MG.

\section{Materials and methods}

\section{Investigated area}

The Greater Cairo contains three interlocked cities Cairo, Giza, and Kalyoubia $\left(30^{\circ} 03^{\prime} \mathrm{N}\right.$ $31^{\circ} 22^{\prime} \mathrm{E}$ ), as shown in Fig. 1. Cairo is the capital of Egypt and the largest city in the Middle East, and the second-largest in Africa after Lagos. Its metropolitan area is the $15^{\text {th }}$ largest in the world.

139 Located near the Nile Delta, it was founded in 969 CE. Based on the recent statistics reported by 140 CAPMS (2019), Cairo, Giza, and Kalyoubia are 100, 60, $42 \%$ are urban zones, respectively. The continuous expansion of the urbanization around GC involves significant geomorphic impacts and

142 has unfavorable geomorphological consequences (Csima, 2010). In addition to the industrial and

143 urbanization expansion and dense population, Egypt houses almost 7.9 M vehicles, and out of this 144 figure, Cairo is the governorate with the largest number of vehicles (2.2 million), followed by Giza 145 (921500) and Alexandria (702100). Vehicles and vehicular traffic emissions represent the main 146 pollution sources. Moreover, GC is surrounded by two industrial zones from the northern and southern borders (Shoubra El-Kheima and Helwan, respectively), which significantly increase the concentrations of air pollutants (Farahat, 2011). For comparison purposes, a governorate Menoufia $\left(30^{\circ} 38^{\prime} 14.88^{\prime \prime} \mathrm{N}, 30^{\circ} 54^{\prime} 53.73 " \mathrm{E}\right)$ was examined in terms of metal-air pollution where Menoufia

150 is a rural region and characterized by agricultural activities. The Menoufia Governorate population 151 is about 4.5 million, and the population density is $1807 \mathrm{pop} / \mathrm{km}^{2}$ (CAPMS, 2019). Menoufia 152 Governorate is characterized by a rural nature and an urbanized zone of $21.2 \%$. It is located $60 \mathrm{~km}$ 153 North-West of Cairo. 


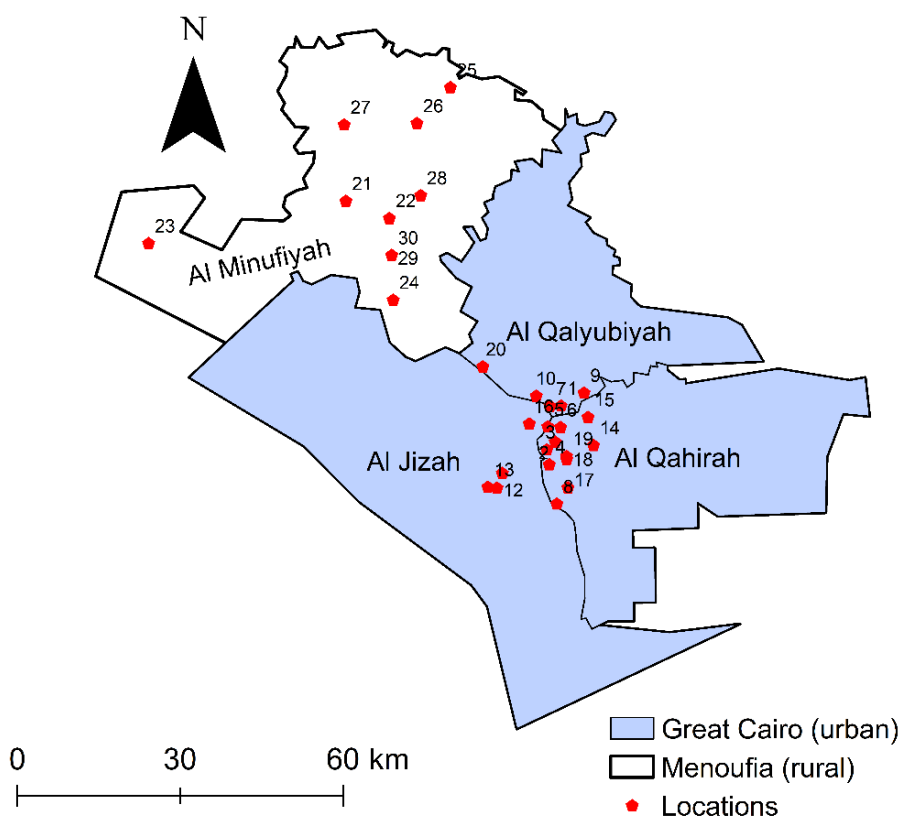

Fig. 1 map of sampling localities

Sampling strategy

Thirty evergreen tree leaves samples of E. globulus and F. benjamina and twenty-nine of

160 adjacent soil samples were collected from Greater Cairo Metropolitan and Menoufia Governorate,

161 respectively. The samples were collected from various districts in Greater Cairo and Menoufia

162 Governorate. A total of 20 leaf samples were collected from Greater Cairo, and ten samples were

163 collected from Menoufia Governorate. Leaves from the two species of trees, E. Globulus and F.

164 Benjamina were selected because they are found in a widespread distribution in Egypt. E. Globulus and F. Benjamina are characterized by their ability to uptake of particulates more than other tree species at the same sampling site. They are suitable for biomonitoring in dry countries (FreerSmith et al., 2004). Leaves were randomly taken from all sides of the trees at approximately 2 meters height. The sampling process was conducted according to the recommendations and guidelines reported by Tomašević et al. (2011); Yalaltdinova et al. (2018). The full description of the sample number and the corresponding collecting points is provided in Table 1SM (Supplementary Materials).

\section{Sample preparation}

The tree leaves were triple washed with distilled water and dried at room temperature. Then, they dried in the drying oven at a temperature of 40 degrees for seven days. The dried samples were grinded into agate grinders. Two aliquots, each of $0.3 \mathrm{~g}$ of the obtained powder was packed in polyethylene zipped bags. Samples were pressed in the mechanical piston to obtain pellets of $1.5 \mathrm{~cm}$ diameter and $0.3 \mathrm{~cm}$ height. These pellets were packed in Aluminum cups and 
polyethylene bags for long and short-lived isotopes irradiation. Soil samples were cleaned from plants and roots. Later on, they were air-dried at a temperature of $105{ }^{\circ} \mathrm{C}$ for 4 hours to a constant weight, crushed with a non-metal grinder. The grinder was thoroughly cleaned and dried after every grinding to avoid any contamination among samples, as reported by Al-Khashman et al. (2011).

183 For atomic absorption spectrometry (AAS), an aliquot of $0.2 \mathrm{~g}$ of tree leaves was placed in a Teflon vessel and decomposed with $3 \mathrm{~mL}$ of concentrated nitric acid $\left(\mathrm{HNO}_{3}\right)$ and $2 \mathrm{~mL}$ of hydrogen peroxide $\left(\mathrm{H}_{2} \mathrm{O}_{2}\right)$ in a microwave digestion system (Mars; CEM, Matthews, NC, USA) for complete digestion. A detailed description of the digestion mechanism was published elsewhere by Chaligava et al. (2020); Madadzada et al. (2019).

\section{Analytical techniques}

A variety of analytical methods can be reliably utilized for the assessment of the elemental composition in the tree leaves and soil samples. These several analytical techniques available, each of which offers complimentary advantages such as X-ray fluorescence XRF and X-ray diffraction XRD. Among these techniques, instrumental neutron activation analysis INAA and atomic absorption spectrometry AAS. Instrumental neutron activation analysis INAA is a powerful technique in determining the inorganic pollutants in tree leaves and soil. Likewise, the complementary analytical method AAS was employed mainly to determine $\mathrm{Cu}, \mathrm{Cd}$, and $\mathrm{Pb}$ in tree leaves.

Leaf samples were subjected to neutron activation analysis at the IBR-2 reactor of the FLNP JINR in Dubna, Russia. The detailed characteristics of the irradiation channels are reported elsewhere by Frontasyeva and Pavlov (2005). The samples were irradiated twice to determine the elements of short and long-lived isotopes. For short-lived isotopes SLI, each sample was irradiated for $3 \mathrm{~min}$ and measured for $15 \mathrm{~min}$. Likewise, the long-lived ones were irradiated for three days under neutron flux of $1.8 \times 10^{11} \mathrm{n} / \mathrm{cm}^{2} \cdot \mathrm{sec}$. Later on, the samples were repacked and measured twice. The first measurement was performed after four days of decay for $30 \mathrm{~min}$, and this is the so-called first long-lived isotopes LLI1. While the second one was achieved after 20 days of decay for $1.5 \mathrm{~h}$, and this is called the second long-lived isotopes LLI2 (Chaligava et al., 2020; Madadzada et al., 2019; Sarhan et al., 2019).

AAS was used to determine the concentrations of $\mathrm{Cu}, \mathrm{Cd}$, and $\mathrm{Pb}$ in tree leaves samples via iCE 3300 AAS Atomic Absorption Spectrometer with electrothermal (graphite furnace) atomization (Thermo Fisher Scientific, Waltham, MA, USA). 


\section{Assessment of pollution, human toxicity, and terrestrial ecotoxicity levels}

\section{Enrichment factor EF}

To avoid the significant variations in the absolute values that may mislead the interpretation of the relationships between elements, the concentrations of the entire set of elements is normalized to the corresponding values in the upper continental crust UCC or in the soil

$$
\mathrm{EF}=\frac{\left[C_{x} / C_{A l}\right] \text { tree leaves }}{\left[C_{S} / C_{A l}\right] \text { Soil }}
$$

where $C_{x}$ is the concentration of the elements $\mathrm{x}$ of concern in tree leaves. Whereas, $C_{s}$ stands for the concentration of the same element in soil. Both concentrations are normalized to $\mathrm{Al}$ in tree leaves and soil, respectively (Bargagli, 1989). The interpretation of enrichment factor EF and the corresponding categories is provided in Table 2 SM (Supplementary Materials)

\section{Pollution load index PLI}

Before the calculation of PLI, the contamination factor CF for every single element was calculated as the ratio of the concentration of each element over the corresponding value in the reference plant RF (Markert, 1992) or upper continental crust UCC (Rudnick and Gao, 2014)for plants and soil, respectively. PLI is given as (Kowalska et al., 2018; Varol, 2011).

$$
\mathrm{PLI}=\sqrt[n]{\prod_{i=1}^{n} \mathrm{CF}_{i}}
$$

When PLI is greater than unity, it suggests that pollution exists and vice versa.

\section{Potential ecological risk index PER}

PER has been used to differentiate and sort out which studied areas should be paid attention in terms of pollution extent (Hakanson, 1980). The formula of $P E R_{f}^{i}$ for a single metal pollution is

233 deduced as follows:

$$
P E R_{f}^{i}=C_{f}^{i} \times T_{f}^{i}
$$


where $P E R_{f}^{i}$ is a potential ecological risk index, $C_{f}^{i}$ is the contamination factor, and $T_{f}^{i}$ is

237 the "toxic-response" coefficient for the given single metal/metalloid. The corresponding $T_{f}^{i}$ listed 238 values are, $\mathrm{Zn}=1, \mathrm{As}=10, \mathrm{Cr}=2, \mathrm{Ni}=\mathrm{Cu}=5$, and $\mathrm{Cd}=30$ (Badawy et al., 2018; Hakanson, 239 1980).

\section{Risk Index RI}

The potential toxicity response index (RI), a single-entity index combining all of the metals of interest, is calculated as:

$$
R I=\sum P E R_{f}^{i}
$$

where RI is the sum of the $P E R_{f}^{i}$ for each metal of interest (Hakanson, 1980). The categories are interpreted and given in Table 3SM (Supplementary Materials) (Badawy et al., 2018; Hakanson, 1980; Karuppasamy et al., 2017).

\section{Human and ecotoxicity assessment}

In the life cycle impact assessment methods, we used the ReCiPe method and characterization factors (De Schryver A and Goedkoop M, 2009; Dekker et al., 2019; Huijbregts M.A.J. and Van Zelm R, 2009; Struijs et al., 2010; Struijs J. et al., 2009), which comprises harmonized category indicators at the midpoint and the endpoint level. The characterization factors quantify the potential impacts that inputs and releases have on specific impact categories in common equivalence units. The below equation shows the characterization process.

$$
I_{m}=\sum_{i} Q_{m i} m_{i}
$$

255

where $m i$ is the magnitude of intervention $i$ (e.g., the mass of heavy metal elements released to air), $Q_{m i}$ the characterization factor that connects intervention $i$ with midpoint impact category $m$, and $I_{m}$ the indicator results for midpoint impact category $m$. (De Schryver A and Goedkoop M, 2009; Goedkoop and Spriensma, 2001).

In the human toxicity and terrestrial ecotoxicity category in the ReCiPe method and characterization factors, many elements are considered in the air compartment (high population and low population area). In this study, $\mathrm{Mg}, \mathrm{V}, \mathrm{Cr}, \mathrm{Mn}, \mathrm{Co}, \mathrm{Ni}, \mathrm{Zn}, \mathrm{As}, \mathrm{Br}, \mathrm{Ag}, \mathrm{Sb}$, and Ba elements (12 elements) were matched, and characterization results were calculated. In the soil compartment (agriculture soil, forestry soil, and industrial soil), $\mathrm{Mg}, \mathrm{Al}, \mathrm{Cl}, \mathrm{As}, \mathrm{Se}, \mathrm{Br}, \mathrm{Cd}, \mathrm{Sb}, \mathrm{I}$, and $\mathrm{Ba}$ elements (10 elements) were matched, and characterization results were calculated. 


\section{Statistical data analysis}

All the statistical analyses of chemical data and graphing were performed using the 267 statistical package R (R Core Team, 2016). The data were handled in MS office Excel. GIS 268 technology was used to map the spatial distribution of the pollution patterns. The data were 269 interpolated based on the inverse distance weighting IDW method.

\section{$270 \quad$ Results and discussion}

\section{Metal concentrations and inter-correlation}

A total of 34 and 40 elements were determined in the examined two evergreen tree species

273 (E. globulus and F. benjamina) and adjacent soil samples, respectively. The full descriptive 274 statistics of the concentrations of the determining elements are stipulated in Tables 1 and 2 for 275 plant species and soil, respectively.

276

Table 1: Concentrations of elements (mean \pm SD) tree leaves samples collected from 278 Greater Cairo GC and Menoufia. The corresponding values of the Reference Plant RP reported by 279 Markert (1992) were added for comparison purposes. All values expressed in mg/kg.

\begin{tabular}{|c|c|c|c|c|c|}
\hline \multirow{2}{*}{ Element } & \multirow{2}{*}{$\frac{\text { Eucalyptus Globulus }}{\text { GC }}$} & \multicolumn{3}{|c|}{ Ficus benjamina } & \multirow{2}{*}{$\mathbf{R P}$} \\
\hline & & MG & GC & MG & \\
\hline $\mathrm{Na}$ & $2842 \pm 1232.39$ & $2900 \pm 1052.21$ & $2036.9 \pm 1388.73$ & $2536.4 \pm 1250.81$ & 150 \\
\hline $\mathrm{Mg}$ & $453.8 \pm 109.35$ & $434.4 \pm 131.24$ & $521.7 \pm 111.7$ & $676.8 \pm 210.3$ & 2000 \\
\hline $\mathrm{Al}$ & $871.1 \pm 331.98$ & $1012.2 \pm 208.47$ & $1262.3 \pm 535.69$ & $3064 \pm 2647.06$ & 80 \\
\hline $\mathrm{Cl}$ & $6816 \pm 3308.02$ & $5094 \pm 861.41$ & $8288 \pm 2595.85$ & $5972 \pm 1541.55$ & 2000 \\
\hline $\mathrm{K}$ & $10205 \pm 6705.75$ & $6694 \pm 2219.62$ & $18470 \pm 5659.02$ & $12428 \pm 4629.03$ & 19000 \\
\hline $\mathrm{Ca}$ & $23400 \pm 9872.07$ & $19740 \pm 8983.48$ & $37990 \pm 10358.41$ & $41220 \pm 14875.72$ & 10000 \\
\hline $\mathrm{Sc}$ & $0.2 \pm 0.09$ & $0.47 \pm 0.16$ & $0.26 \pm 0.21$ & $0.79 \pm 1.08$ & 0.02 \\
\hline $\mathrm{Ti}$ & $119.9 \pm 41.7$ & $116 \pm 50.88$ & $156.2 \pm 84.95$ & $375 \pm 353.85$ & 5 \\
\hline $\mathrm{V}$ & $2.67 \pm 1.13$ & $2.54 \pm 0.52$ & $5.38 \pm 4.91$ & $7.89 \pm 6.66$ & 0.5 \\
\hline $\mathrm{Cr}$ & $2.55 \pm 1.2$ & $3 \pm 0.77$ & $3.37 \pm 2.73$ & $6.72 \pm 7.18$ & 1.5 \\
\hline $\mathrm{Mn}$ & $184.2 \pm 125.54$ & $202 \pm 73.57$ & $30.02 \pm 10.62$ & $123.2 \pm 92.62$ & 200 \\
\hline $\mathrm{Fe}$ & $851 \pm 385.05$ & $1638.4 \pm 653.06$ & $1173.4 \pm 886.45$ & $3597 \pm 3845.02$ & 150 \\
\hline Co & $0.38 \pm 0.16$ & $0.75 \pm 0.19$ & $0.57 \pm 0.65$ & $1.26 \pm 1.32$ & 0.2 \\
\hline $\mathrm{Ni}$ & $4.39 \pm 1.94$ & $4.43 \pm 0.86$ & $3.49 \pm 5.08$ & $4.11 \pm 4.34$ & 1.5 \\
\hline $\mathrm{Cu}$ & $10.95 \pm 3.71$ & $7.35 \pm 0.57$ & $11.04 \pm 2.94$ & $8.66 \pm 1.95$ & 10 \\
\hline $\mathrm{Zn}$ & $44.58 \pm 33.14$ & $23.08 \pm 8.4$ & $32.31 \pm 19.8$ & $32.96 \pm 26.33$ & 50 \\
\hline As & $1.14 \pm 0.6$ & $0.81 \pm 0.3$ & $1.13 \pm 0.75$ & $1.05 \pm 0.53$ & 0.1 \\
\hline $\mathrm{Se}$ & $0.32 \pm 0.07$ & $0.31 \pm 0.07$ & $0.29 \pm 0.08$ & $0.21 \pm 0.15$ & 0.02 \\
\hline $\mathrm{Br}$ & $26.6 \pm 17.8$ & $27.56 \pm 7.92$ & $31.49 \pm 15.43$ & $16.84 \pm 5.63$ & 4 \\
\hline $\mathrm{Rb}$ & $2.9 \pm 2.01$ & $2.05 \pm 0.44$ & $5.59 \pm 4.37$ & $3.6 \pm 2.89$ & 50 \\
\hline
\end{tabular}




\begin{tabular}{|c|c|c|c|c|c|}
\hline $\mathrm{Sr}$ & $125.1 \pm 81.89$ & $80.66 \pm 38.73$ & $357 \pm 255.85$ & $176.4 \pm 41.53$ & 50 \\
\hline $\mathrm{Cd}$ & $0.14 \pm 0.14$ & $0.19 \pm 0.18$ & $0.17 \pm 0.19$ & $0.25 \pm 0.13$ & 0.05 \\
\hline $\mathrm{Sb}$ & $0.2 \pm 0.14$ & $0.06 \pm 0.01$ & $0.29 \pm 0.18$ & $0.14 \pm 0.09$ & 0.1 \\
\hline I & $0.92 \pm 0.32$ & $1.04 \pm 0.21$ & $0.82 \pm 0.27$ & $1.36 \pm 0.78$ & 3 \\
\hline Cs & $0.02 \pm 0.01$ & $0.04 \pm 0.01$ & $0.03 \pm 0.02$ & $0.06 \pm 0.07$ & 0.2 \\
\hline $\mathrm{Ba}$ & $20.1 \pm 13.4$ & $22.88 \pm 1.36$ & $38.51 \pm 49.21$ & $33.4 \pm 21.57$ & 40 \\
\hline $\mathrm{La}$ & $0.53 \pm 0.23$ & $0.77 \pm 0.29$ & $0.68 \pm 0.52$ & $1.2 \pm 1.47$ & 0.2 \\
\hline $\mathrm{Sm}$ & $0.07 \pm 0.02$ & $0.15 \pm 0.05$ & $0.09 \pm 0.07$ & $0.33 \pm 0.5$ & 0.04 \\
\hline $\mathrm{Tb}$ & $0.03 \pm 0.02$ & $0.03 \pm 0.01$ & $0.04 \pm 0.04$ & $0.05 \pm 0.06$ & 0.008 \\
\hline $\mathrm{Hf}$ & $0.08 \pm 0.03$ & $0.11 \pm 0.05$ & $0.13 \pm 0.12$ & $0.2 \pm 0.26$ & 0.05 \\
\hline $\mathrm{Ta}$ & $0.02 \pm 0.01$ & $0.03 \pm 0.01$ & $0.02 \pm 0.02$ & $0.04 \pm 0.05$ & 0.001 \\
\hline $\mathrm{Pb}$ & $3.74 \pm 2$ & $1.24 \pm 0.47$ & $5.75 \pm 3.44$ & $9.09 \pm 10.02$ & 1 \\
\hline Th & $0.37 \pm 0.37$ & $0.18 \pm 0.06$ & $0.39 \pm 0.28$ & $0.24 \pm 0.23$ & 0.005 \\
\hline $\mathrm{U}$ & $0.05 \pm 0.02$ & $0.06 \pm 0.02$ & $0.05 \pm 0.03$ & $0.08 \pm 0.09$ & 0.01 \\
\hline
\end{tabular}

281

282 Table 2: Concentrations of elements (mean \pm SD) soil samples collected from Greater Cairo GC

283 and Menoufia. The corresponding values of the upper continental crust RP reported by Rudnick

284 and Gao (2014) were added for comparison purposes. All values expressed in mg/kg.

285

\begin{tabular}{|c|c|c|c|c|c|c|c|}
\hline Element & GC & MG & UCC & Element & GC & MG & UCC \\
\hline $\mathrm{Na}$ & $6142.5 \pm 4291.2$ & $11837.8 \pm 3558.6$ & 24258.57 & $\mathrm{Zr}$ & $193.1 \pm 89.6$ & $264.1 \pm 88$ & 193 \\
\hline $\mathrm{Mg}$ & $14671.5 \pm 8356.8$ & $24077.8 \pm 10518.5$ & 14953.85 & $\mathrm{Ag}$ & $0.5 \pm 0.3$ & $0.9 \pm 0.2$ & 0.053 \\
\hline $\mathrm{Al}$ & $24760 \pm 16051$ & $41077.8 \pm 19377.9$ & 81510.71 & $\mathrm{Sb}$ & $1.5 \pm 1.4$ & $1.5 \pm 0.9$ & 0.4 \\
\hline $\mathrm{Si}$ & $445900 \pm 75377.6$ & $353444.4 \pm 62440.2$ & 311405.14 & Cs & $0.6 \pm 0.4$ & $1.1 \pm 0.5$ & 4.9 \\
\hline $\mathrm{Cl}$ & $3750.9 \pm 5962.6$ & $8179.3 \pm 10127.1$ & 370 & $\mathrm{Ba}$ & $373.5 \pm 281.2$ & $205.8 \pm 95.5$ & 628 \\
\hline $\mathrm{K}$ & $6678 \pm 2357.6$ & $10653.3 \pm 3127.5$ & 23244.16 & $\mathrm{La}$ & $13 \pm 7.4$ & $22 \pm 9.3$ & 31 \\
\hline $\mathrm{Ca}$ & $37350 \pm 14065.9$ & $37066.7 \pm 11827.6$ & 25657.49 & $\mathrm{Ce}$ & $30.2 \pm 18.7$ & $63.9 \pm 30.8$ & 63 \\
\hline $\mathrm{Sc}$ & $8.1 \pm 7.1$ & $17 \pm 9.6$ & 14 & $\mathrm{Nd}$ & $10 \pm 6.7$ & $20.7 \pm 11.4$ & 27 \\
\hline $\mathrm{Ti}$ & $4477 \pm 3102.5$ & $7862.2 \pm 3915.5$ & 3835.79 & $\mathrm{Sm}$ & $4.8 \pm 3$ & $5.5 \pm 2.4$ & 4.7 \\
\hline $\mathrm{V}$ & $84.2 \pm 64.2$ & $137.2 \pm 67.9$ & 97 & $\mathrm{Eu}$ & $0.7 \pm 0.5$ & $1.4 \pm 0.6$ & 1 \\
\hline $\mathrm{Cr}$ & $50 \pm 28.3$ & $85.4 \pm 23.2$ & 92 & $\mathrm{Gd}$ & $0.5 \pm 0.3$ & $1.3 \pm 1.7$ & 4 \\
\hline Mn & $471.9 \pm 322.9$ & $1007.2 \pm 302.1$ & 774.46 & $\mathrm{~Tb}$ & $0.4 \pm 0.3$ & $0.7 \pm 0.3$ & 0.7 \\
\hline $\mathrm{Fe}$ & $27846 \pm 21140.3$ & $75388.9 \pm 29845.2$ & 39175.06 & Dy & $3.4 \pm 1.3$ & $4.4 \pm 1.6$ & 3.9 \\
\hline $\mathrm{Co}$ & $11.7 \pm 9.8$ & $24.5 \pm 11.9$ & 17.3 & $\mathrm{Yb}$ & $3.6 \pm 2.5$ & $2.8 \pm 1$ & 1.96 \\
\hline $\mathrm{Ni}$ & $32 \pm 25.3$ & $51.5 \pm 17.6$ & 47 & $\mathrm{Hf}$ & $4.8 \pm 2.2$ & $6.7 \pm 2.1$ & 5.3 \\
\hline $\mathrm{Zn}$ & $170.1 \pm 147.2$ & $70.2 \pm 40$ & 67 & $\mathrm{Ta}$ & $0.7 \pm 0.4$ & $1.3 \pm 0.7$ & 0.9 \\
\hline As & $2.9 \pm 1.2$ & $4.3 \pm 1.3$ & 4.8 & $\mathrm{~W}$ & $1.1 \pm 0.6$ & $2.6 \pm 0.6$ & 1.9 \\
\hline
\end{tabular}




\begin{tabular}{cccccccc}
$\mathrm{Br}$ & $7.5 \pm 4.6$ & $9.8 \pm 4.4$ & 1.6 & $\mathrm{Au}$ & $0.017 \pm 0.02$ & $0.006 \pm 0.004$ & 0.0015 \\
$\mathrm{Rb}$ & $21 \pm 12$ & $39 \pm 13.6$ & 84 & $\mathrm{Th}$ & $2.9 \pm 1.5$ & $5.2 \pm 2.1$ & 10.5 \\
$\mathrm{Sr}$ & $204.4 \pm 94.6$ & $296 \pm 47.2$ & 320 & $\mathrm{U}$ & $1 \pm 0.3$ & $1.6 \pm 0.3$ \\
\hline
\end{tabular}

286 The interaction of the mean values in both tree species in GC (urban) shows that the mean

287 values of the obtained elements are in a good matching to each other's except for $\mathrm{Ca}, \mathrm{K}, \mathrm{Cl}, \mathrm{Na}$,

$288 \mathrm{Al}, \mathrm{Fe}$, and $\mathrm{Mg}$ found to be higher in F. benjamina than in E. globulus. The major elements are

289 shown to be accumulated in F. benjamina higher than E. globulus except for Na. Overall, the

290 descending order of the elements accumulated by the two species are given as $\mathrm{Ca}>\mathrm{K}>\mathrm{Cl}>\mathrm{Na}$

$291>\mathrm{Al}>\mathrm{Fe}>\mathrm{Mg}>\mathrm{Mn}>\mathrm{Sr}>\mathrm{Ti}>\mathrm{Zn}>\mathrm{Br}>\mathrm{Ba}>\mathrm{Cu}>\mathrm{Ni}>\mathrm{Pb}>\mathrm{Rb}>\mathrm{V}>\mathrm{Cr}>\mathrm{As}>\mathrm{I}>\mathrm{La}>$

$292 \mathrm{Co}>\mathrm{Th}>\mathrm{Se}>\mathrm{Sc}>\mathrm{Sb}>\mathrm{Cd}>\mathrm{Hf}>\mathrm{Sm}>\mathrm{U}>\mathrm{Tb}>\mathrm{Cs}>\mathrm{Ta}$.

293 Likewise, the mean values of elements in the two-tree species in GM (rural) show that all

294 the concentrations of the obtained elements in F. benjamina are higher than in E. globulus except

$295 \mathrm{Na}, \mathrm{Mn}, \mathrm{Br}, \mathrm{Ni}$, and $\mathrm{Se}$ are observed to be higher in E. globulus versus F. benjamina. The

296 concentrations of the major elements viz., $\mathrm{Ca}, \mathrm{K}, \mathrm{Cl}, \mathrm{Fe}, \mathrm{Al}, \mathrm{Na}, \mathrm{Mg}$, Ti, and $\mathrm{Sr}$. The mean element

297 content in the two species of plants is described in the descending order of $\mathrm{Ca}>\mathrm{K}>\mathrm{Cl}>\mathrm{Fe}>\mathrm{Al}>$

$298 \mathrm{Na}>\mathrm{Mg}>\mathrm{Ti}>\mathrm{Sr}>\mathrm{Mn}>\mathrm{Ba}>\mathrm{Zn}>\mathrm{Br}>\mathrm{Pb}>\mathrm{Cu}>\mathrm{V}>\mathrm{Cr}>\mathrm{Ni}>\mathrm{Rb}>\mathrm{I}>\mathrm{Co}>\mathrm{La}>\mathrm{As}>\mathrm{Sc}>\mathrm{Sm}>\mathrm{Cd}>$

$299 \mathrm{Th}>\mathrm{Se}>\mathrm{Hf}>\mathrm{Sb}>\mathrm{U}>\mathrm{Cs}>\mathrm{Tb}>\mathrm{Ta}$. Generally, the concentrations of obtained elements are noticed

300 to be higher in F. benjamina than in E. globulus.

301 Similarly, the concentration mean values $\mathrm{mg} / \mathrm{kg}$ of the adjacent soil samples were 302 determined in Greater Cairo GC (urban) and Menoufia Governorate MG (rural) and the results 303 show that the mean values are in line for the two examined governorates. The major elements 304 namely $\mathrm{Si}, \mathrm{Ca}, \mathrm{Fe}, \mathrm{Al}, \mathrm{Mg}, \mathrm{K}, \mathrm{Na}$, and Ti were observed to be higher in MG than in GC, except $\mathrm{Si}$ 305 and $\mathrm{Ca}$ were higher in GC than in GM. The descending order of the elements in GC and GM is 306 given as $\mathrm{Si}>\mathrm{Ca}>\mathrm{Fe}>\mathrm{Al}>\mathrm{Mg}>\mathrm{K}>\mathrm{Na}>\mathrm{Ti}>\mathrm{Cl}>\mathrm{Mn}>\mathrm{Ba}>\mathrm{Sr}>\mathrm{Zr}>\mathrm{Zn}>\mathrm{V}>\mathrm{Cr}>\mathrm{Ni}>\mathrm{Ce}>\mathrm{Rb}>$ $307 \mathrm{La}>\mathrm{Co}>\mathrm{Nd}>\mathrm{Sc}>\mathrm{Br}>\mathrm{Hf}>\mathrm{Sm}>\mathrm{Yb}>\mathrm{Dy}>\mathrm{As}>\mathrm{Th}>\mathrm{Sb}>\mathrm{W}>\mathrm{U}>\mathrm{Eu}>\mathrm{Ta}>\mathrm{Cs}>\mathrm{Ag}>\mathrm{Gd}>\mathrm{Tb}>$ $308 \mathrm{Au}$, and $\mathrm{Si}>\mathrm{Fe}>\mathrm{Al}>\mathrm{Ca}>\mathrm{Mg}>\mathrm{Na}>\mathrm{K}>\mathrm{Cl}>\mathrm{Ti}>\mathrm{Mn}>\mathrm{Sr}>\mathrm{Zr}>\mathrm{Ba}>\mathrm{V}>\mathrm{Cr}>\mathrm{Zn}>\mathrm{Ce}>\mathrm{Ni}>\mathrm{Rb}>$ $309 \mathrm{Co}>\mathrm{La}>\mathrm{Nd}>\mathrm{Sc}>\mathrm{Br}>\mathrm{Hf}>\mathrm{Sm}>\mathrm{Th}>\mathrm{Dy}>\mathrm{As}>\mathrm{Yb}>\mathrm{W}>\mathrm{U}>\mathrm{Sb}>\mathrm{Eu}>\mathrm{Ta}>\mathrm{Gd}>\mathrm{Cs}>\mathrm{Ag}>\mathrm{Tb}>$ $310 \mathrm{Au}$, for GC (urban) and MG (rural), respectively. The concentrations of the elements in $F$. 311 benjamina are higher than in E. globulus and in MG is higher than in GC.

312 The obtained concentrations of the elements in tree leaves and soil were normalized to the 313 corresponding values of the elements in the reference plants RF reported by Markert (1992) and 314 upper continental crust UCC reported by Rudnick and Gao (2014). For tree leaf species, the 315 obtained results show significant concentrations of Th, Ti, Ta, Al, Se, Na, Sc, As, V, and Br; Th, $316 \mathrm{Ti}, \mathrm{Na}, \mathrm{Ta}, \mathrm{Se}, \mathrm{As}, \mathrm{Al}, \mathrm{Sc}, \mathrm{Br}$, and $\mathrm{Fe}$ in $\mathrm{GC}$ samples for F. benjamina and E. globulus, respectively.

317 Whereas, significant concentrations are observed for Ti, Th, Ta, Sc, Al, Fe, Na, V, As, and Se for 
F. benjamina and $\mathrm{Th}, \mathrm{Ta}, \mathrm{Sc}, \mathrm{Ti}, \mathrm{Na}, \mathrm{Se}, \mathrm{Al}, \mathrm{Fe}, \mathrm{As}$, and $\mathrm{Br}$ for E. globulus in MG. These findings are box plotted in Fig. 2 A). Overall, the accumulated elements by $F$. benjamina is slightly higher than in E. globulus in GC and MG. While in terms of the investigated area, the concentrations of elements in MG is considerably higher than in GC.

Similarly, the boxplot illustrated in Fig. 2 B) shows remarkable concentrations in the studied soil in $\mathrm{GC}$ for $\mathrm{Au}, \mathrm{Cl}, \mathrm{Ag}, \mathrm{Br}, \mathrm{Sb}, \mathrm{Zn}$, and $\mathrm{Yb}$. While, the concentrations of $\mathrm{Cl}, \mathrm{Ag}, \mathrm{Br}$, $\mathrm{Au}, \mathrm{Sb}, \mathrm{Ti}$, and $\mathrm{Fe}$ were noticed to be higher than those in the corresponding values reported by (Rudnick and Gao, 2014) for UCC. To sum up, the concentrations of the elements in the studied soil are significantly higher in MG than GC.

To test the differences between the mean values of the concentrations in tree species and soil in different areas (rural and urban) and validate the previous findings, a Tukey test of pairwise comparisons was implemented as shown in Table 3. The Tukey test was used to differentiate the differences in the mean values of the elements in different tree species in different areas. At a significance level of 0.05 , the probabilities of rural MG vs urban GC municipalities are ( $p=$ $0.03973)$ and the probabilities of $F$. Benjamina vs E. Globulus are $(p=0.03432)$. Both of the probabilities are lower than the significant level, and this leads to rejecting the null hypothesis and concluding that there are significant differences in mean values for these tree species and areas. Similarly, the probability of rural vs urban areas in the case of soil is $p=0.02615$, which suggests the same hypothesis.

Table 3: Tukey Test for mean comparison

There are significant differences in all cases $(p<0.05)$

\begin{tabular}{|c|c|c|c|}
\hline \multirow[b]{3}{*}{$P$-Value } & \multicolumn{2}{|r|}{ Vegetation } & Soil \\
\hline & Rural - Urban & F. Benjamina -E. Globulus & Rural - Urban \\
\hline & 0.039 & 0.034 & 0.026 \\
\hline
\end{tabular}

As a summing up, the mean values of elements in tree leaves (Ta, Hf, Tb, Sm, La, Sr, Ni, $\mathrm{Co}, \mathrm{Cr}, \mathrm{Ca}$, and $\mathrm{Cl})$ are at least three times higher and (U, Br, Na, Se, As, Fe, V, Sc, and Al) are 510 times higher than those reported in reference plant reported by (Markert, 1992), respectively. The mean values of Th and Ti are higher by 20 times.

Similarly, the overall results for the normalized concentrations of soil samples with the corresponding values reported by Rudnick and Gao (2014) for UCC are higher more than 2-5, 510, and 10-65 for Sb, Cr, Hf, Ni, Ca, Co, Sm, Cl, Cd, La, Sr, Tb, Pb; U, Br, V, Fe, As; and Se, Na, 
A)

Plant type Eucalyptus Globulus Ficus Nitida

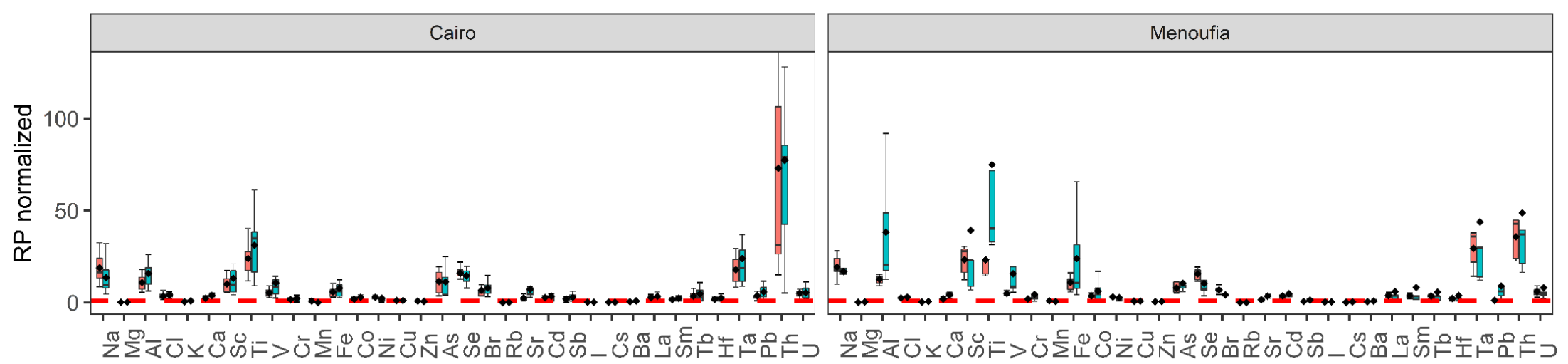

B)

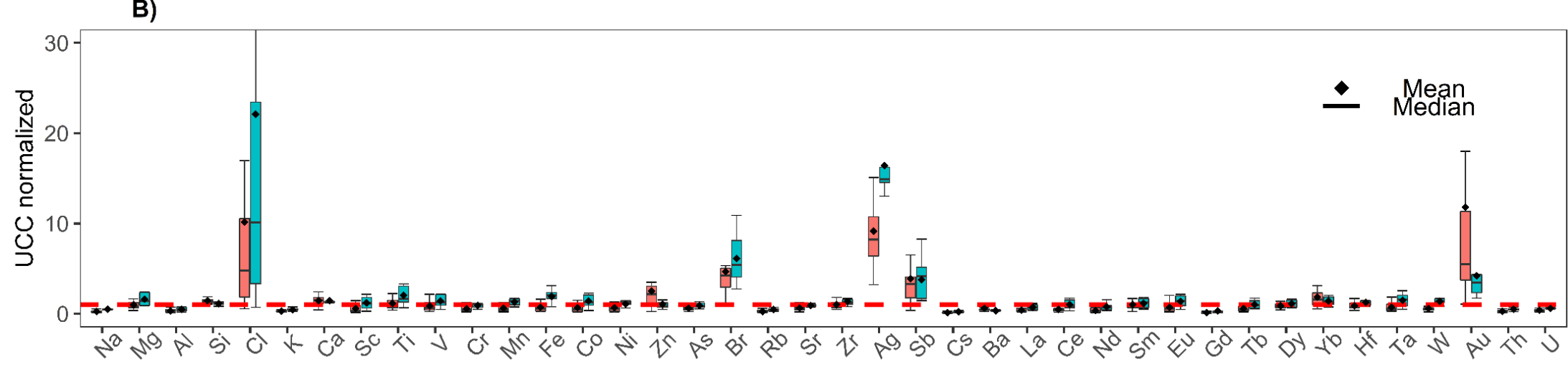

Location Cairo Menoufia

Fig. 2: Box-plots illustrating the distribution of investigated elements in Cairo and Menoufia for Eucalyptus globulus and Ficus bejamina. All

concentrations normalized to RP (A) and soil after normalization to UCC B). 


\section{Principal component analysis (PCA)}

The so-called PCA dimensionality reduction technique was used to get more information about geochemical symmetrical elements and their origin. The data was centered log-ratio transformed CLR prior to the implementation of PCA (Badawy et al., 2018; Faith, 2015). The obtained PCAs were plotted and partitioned into clusters using K-means method.

A total of 34 and 34 out of 40 elements were selected to perform PCA for tree species and soil, respectively. Whereas the other elements of soil samples were excluded from the matrix because they tended to form separate groups. PCA was performed for tree species independent of the type of tree leaves and sampling location. For PCA, we assume that the different tree leaves species accumulate the elements of the atmospheric deposition equally. This assumption was proved by plotting the $1^{\text {st }}$ two PCAs for GC and GM, as shown in Fig 1:4 SM (Supplementary materials).

The obtained PCAs based on the aforementioned number of elements, the eigenvalues, and percentage of variance (in parentheses) for the first three dimensions were calculated to be 10.1 (33.5\%), 4.2 (13.8\%), $2.9(9.7 \%)$ in tree species for GC and GM. The first two PCAs express $47.3 \%$ of the data cumulative percentage of the variance. Therefore, the first two dimensions can sufficiently explain the data.

Based on the K-mean method, the $1^{\text {st }}$ two PCAs of the variables were plotted and clustered as in Fig. 3 (A). It is obvious from the figure that four clusters were created and can be described as follows:

- The $1^{\text {st }}$ cluster contains ten elements, namely Sc, Cr, Fe, Co, Cs, La, Sm, Hf, Ta, and U. It is obvious from the elements, of which this cluster was reproduced that there is a significant association of crustal elements. This combination of elements suggests the geogenic provenance of the elements.

- The $2^{\text {nd }}$ cluster includes 11 elements viz., $\mathrm{Mg}, \mathrm{Cl}, \mathrm{K}, \mathrm{Ca}, \mathrm{Cu}, \mathrm{Zn}, \mathrm{Rb}, \mathrm{Sr}, \mathrm{Cd}, \mathrm{Pb}$, and Th. It is clear from the elements that are containing the cluster that they have a mixed source (geogenic and anthropogenic). Besides, the highly toxic potential elements $(\mathrm{Cu}, \mathrm{Cd}$, and $\mathrm{Pb}$ ) have a significant association with this cluster. Mainly, due to the industrialization and urbanization processes.

- The $3^{\text {rd }}$ cluster has three elements; Al, Ti, and V. These elements are often found in the oil and gas production fields. Considerable concentrations of these elements were observed near to Cairo Thermal Power Plant in Shubra El-kheima and El-sayyeda Zainab. These 
regions are characterized by dense populations for GC. Remarkable contributions to these Therefore, the elevated concentrations of the elements containing this cluster may be due to the emission and maintenance processes.

- The $4^{\text {th }}$ cluster is formed from $\mathrm{Na}, \mathrm{Mn}, \mathrm{Ni}, \mathrm{As}, \mathrm{Br}$, and I. It is apparent from the set of the clustered elements that there is a remarkable association of sea elements ( $\mathrm{Na}, \mathrm{Br}$, and I). Whereas, the existence of $\mathrm{Ni}$ and As mainly due to relevant industries to Nickel such as the burning of fossil fuels, wind-blown dust, and brick kilns which was noticed in high concentrations in Shubra El Kheima power station, then in Al Shuhadaa.

Likewise, the $1^{\text {st }}$ two PCAs for grouping the locations are plotted and illustrated in Fig. 3 (B). The biplot revealed two clusters. The produced clusters could be described as follows:

- The $1^{\text {st }}$ group includes 19 locations namely; $1,2,3,5,6,8,11,12,13,14,15,16,17,18$, $19,20,23,25,28$.

- The $2^{\text {nd }}$ cluster contains 11 locations viz., 4, 7, 9, 10, 21, 22, 24, 26, 27, 29, 30

It is clear from fig. 3 (B) that the $1^{\text {st }}$ cluster has a low contribution to the $1^{\text {st }}$ PCA. Whereas a remarkable contribution was noticed for locations \# 23 and 15 for Sadat City (industrial zone) and al-Amireyya (dense population), respectively. Contrariwise, the $2^{\text {nd }}$ cluster has a considerable presentation on the plane. Specifically, locations \# 4, 7, and 27. Based on the description of the locations given in Table 1SM the significant contributions were registered for el-Sayyeda Zainab (dense population), Shubra el-Kheima (power station), and al-Shuhadaa (railway train station), respectively. 


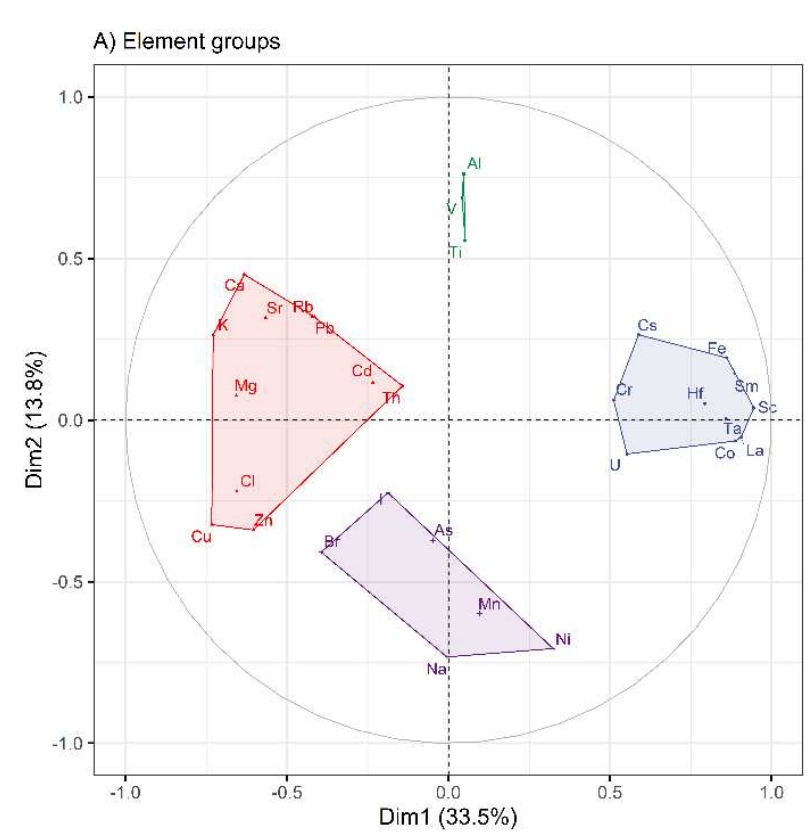

Elements groups 回1 回2 2 回 34

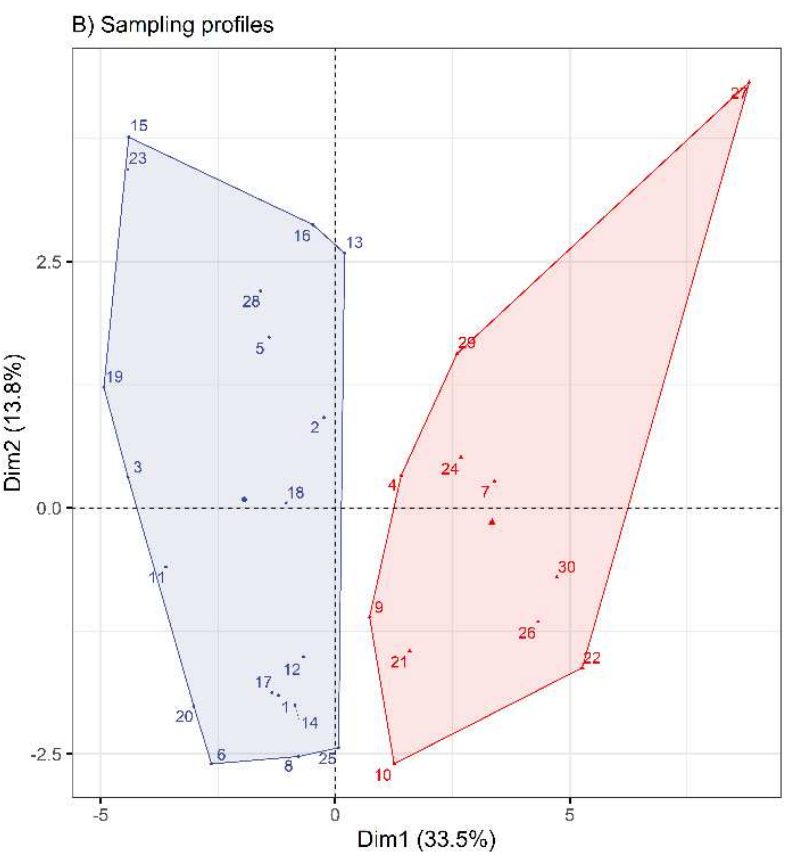

Sampling points 1 回 2
409

410

411

412

413

414

415

416

417

418

419

420

421

422

423

424

425

426

427

428

429

Fig. 3: The Principal component analysis PCA bi-plot of PC1 and PC2 for tree leaves results illustrating the existence of significant clusters of determined elements A) and investigated collecting points B).

To identify the effect that may be raised from the adjacent soil, a total of 34 out of 40 elements were selected to perform PCA, as clearly shown in Fig. 4. The PCAs accounted for 14.7 (43.2\%), $4.2(12.4 \%)$, and $3.4(9.9 \%)$ of the eigenvalues and percentage of variance (in parentheses) for the first three PCAs, respectively. The $1^{\text {st }}$ two PCAs express $55.6 \%$ of the data cumulative percentage of the variance and can sufficiently explain the data.

In a similar manner to the plant analysis, the $1^{\text {st }}$ two PCAs of the variables were plotted and clustered as illustrated in Fig. 4 (A). it is apparent that three clusters were created and can be described as follows:

- The $1^{\text {st }}$ cluster contains nine elements, namely $\mathrm{Na}, \mathrm{Cl}, \mathrm{K}, \mathrm{Ca}, \mathrm{Zn}, \mathrm{As}, \mathrm{Br}, \mathrm{Sb}$, and $\mathrm{Ba}$. The significant contribution of $\mathrm{Na}, \mathrm{Cl}$, and $\mathrm{Br}$ suggests a weathering from sea elements and/or the excess use of fertilizers and pesticides that may lead to an increment of the salinity of the soil. Considerable amounts of these elements were noticed in MG to be higher than in GC. K and Ca be explained by the agricultural nature of MG. While As, $\mathrm{Zn}$, and $\mathrm{Sb}$ most probably due to brick kilns, and vehicles and vehicular traffic emissions (Farahat, 2011). 
- The $2^{\text {nd }}$ cluster is grouped by both geogenic and anthropogenic elements viz., $\mathrm{Mg}, \mathrm{Al}$, $\mathrm{Sc}, \mathrm{Ti}, \mathrm{V}, \mathrm{Cr}, \mathrm{Mn}, \mathrm{Fe}, \mathrm{Co}, \mathrm{Ni}, \mathrm{Rb}, \mathrm{Cs}, \mathrm{La}, \mathrm{Ce}, \mathrm{Sm}, \mathrm{Eu}, \mathrm{Tb}, \mathrm{Ta}$, and Th. This cluster is containing rare earth, oil production, and crustal elements.

- The $3^{\text {rd }}$ grouped from $\mathrm{Sr}, \mathrm{Zr}, \mathrm{Ag}, \mathrm{Hf}, \mathrm{W}$, and $\mathrm{U}$. The set of elements that formed the $3^{\text {rd }}$ cluster is naturally occurring and wind-blown soil.

Likewise, the $1^{\text {st }}$ two PCAs for clustering of locations are plotted and illustrated in Fig. 4 (B). The biplot revealed two clusters and could be described as follows:

- The $1^{\text {st }}$ cluster contains 13 locations namely; 8, 9, 11, 13, 16, 18, 20, 21, 22, 25, 27, 29, and 30. Out of 13 locations, 6 locations are in MG, and the others are in GC. Greatly, clustered locations have common traits. For instance, locations \# 8, 9, 11, 13, 16, 18, and 20 are characterized by heavy traffics, wind-blown sand and dust, high ways, ring road, and significant crustal dust associations (urbanized areas) and are located in GC. Whereas, 21, 22, 25, 27, 29, and 30 are agricultural land (rural areas) and are located in MG.

- The $2^{\text {nd }}$ cluster is grouped from 16 elements viz., $1,2,3,4,5,6,7,10,12,14,15,17$, 19, 23, 24, and 28. This cluster contains locations that are located in GC except for three locations. These findings prove that the locations \# 1, 2, 3, 4, 5, 6, 7, 10, 12, 14, 15,17 , and 19 have similar characterization. These locations mainly are located in GC and are coded for Shubra el-Kheima, Ramsis, Tahrir, el-Sayyeda Zainab, el-Sahel, elSharabeya, Shubra el-Kheima (power station), El-Maadi, Basus, el-Haram, Nasr City, al-Amireyya, el-Basateen, and al-Azhar park, respectively. These places are characterized by heavy traffic and vehicular traffic, densely populated, and wind-blown sand and dust. Due to these facts, industrial objectives and urban waste are the main sources of anthropogenic contamination in investigated areas. Whereas, the locations 23, 24, and 28 are rural regions in MG and are characterized by continuous aerial road dust circulation. 

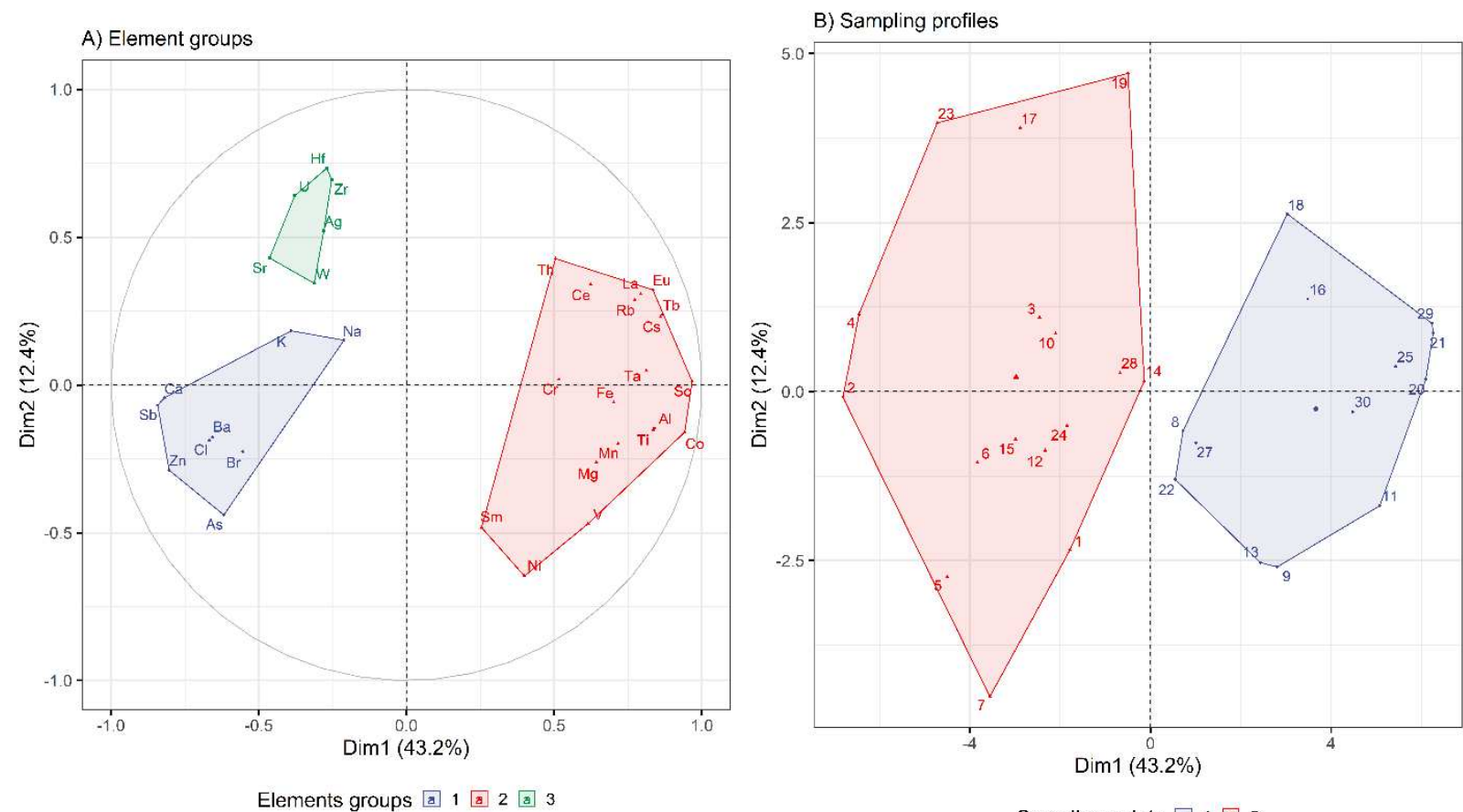

457

460 Fig. 4: The Principal component analysis PCA bi-plot of PC1 and PC2 for soil results illustrating

461 the existence of significant clusters of determined elements A) and investigated collecting points B).

\section{Discriminant analysis DA}

The Sc-La-Th ternary discriminatory diagram (Hallinan, 2012) is illustrated in Fig. 5 a and $465 \mathrm{~b}$ for leaves and soil, respectively. For comparison, the upper continental crust (UCC) data by 466 Rudnick and Gao (2014), and reference plant values by Markert (1992) are added. It is obviously 467 that all the tree leaves points are within the vicinity of UCC, except some samples taken from one 468 of the highest populated regions of Greater Cairo (Shubra El-Kheima) and marked by a red circle 469 on diagram Fig. 5 a. 

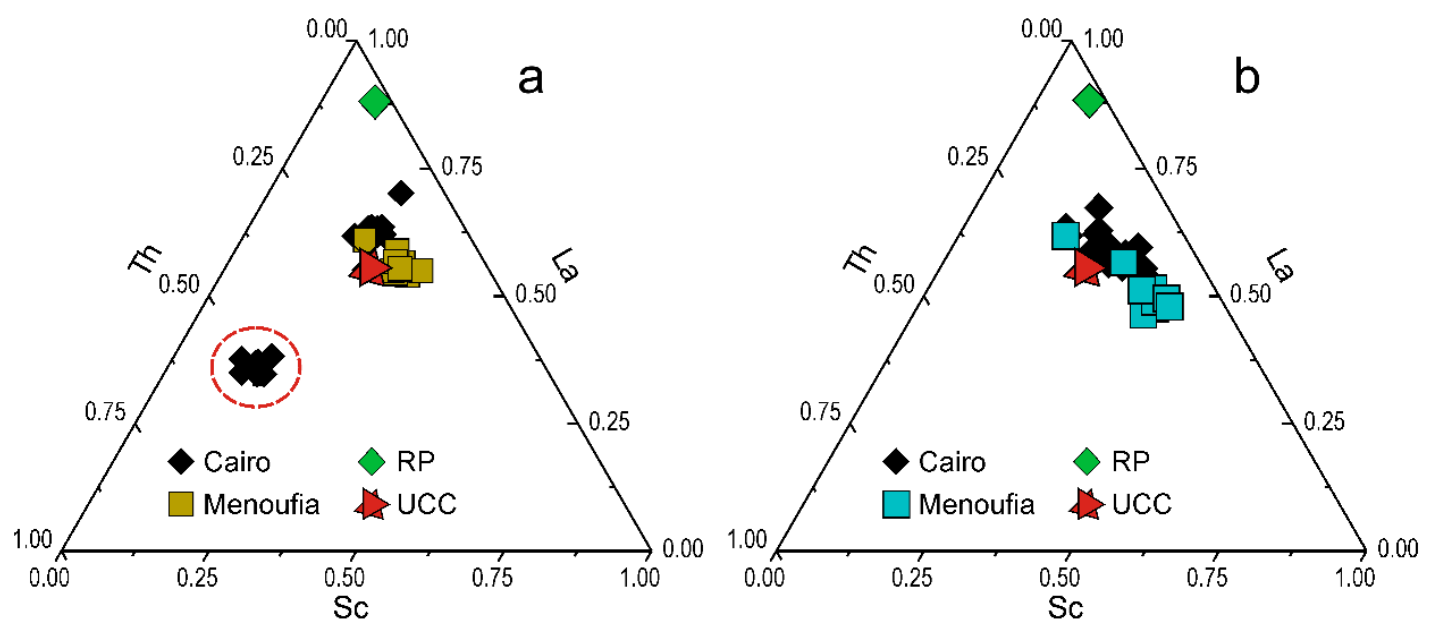

483

484

485

486

487

488

489

490

491

492

493

494

495

496

497

498

499

500

501

502

503

504

505

Fig. 5: Sc-La-Th discriminating diagrams in the case of tree leaves (a) and soils (b). The corresponding values for reference plant RP and upper continental crust reported by Markert (1992) and Rudnick and Gao (2014), respectively were added. It is obviously that all the tree leaves points are within the vicinity of UCC, except some samples taken from one of the highest populated regions of Greater Cairo (Shubra El-Kheima) and marked by a red circle on diagram

(a).

\section{Findings of the pollution extent quantification}

The pollution extent was quantified using the enrichment factor, pollution load index PLI, potential ecological risk PER, and risk index RI. These indices were calculated for both soil, and tree leaves samples from urban and rural regions. The corresponding values reported by Rudnick and Gao (2014) and those reported by Markert (1992) were used for soil and plants, respectively as normalizers.

The calculated results of EF are illustrated in Fig. 6. The crustal association was eliminated using the corresponding values of the adjacent soil and UCC for plants and soil, respectively. In terms of sampling locations, the results of EF show considerable values in $\mathrm{GC}$ and $\mathrm{MG}$ for $\mathrm{Na}, \mathrm{Cl}$, K, Ca, Mn, Zn, As, Br, Sr, and Ba (Fig. 6 A). Whereas E. globulus was observed to accumulate concentration of elements higher than in F. benjamina (Fig. 6 B). These findings are a bit differ from the normalized results and mainly due to the normalizing of the values to the corresponding ones in UCC for soil and RF in plants, respectively. Therefore, in air metal biomonitoring, it is highly recommended to set aside the influence of crustal association using the corresponding values in the soil contamination and then calculate EF (Bargagli et al., 1995). 
It is apparent that the enriched elements have a mixed origin and most probably come from fuel and oil refining (As), woodworking and papermaking or weathering from the sea or fertilizers

$508(\mathrm{Na}, \mathrm{Cl}, \mathrm{Zn})$, Pesticides and herbicides $(\mathrm{Cl}, \mathrm{Br})$, weathering from cement production or brick kilns

509 (Ca). With high possibility, the other elements are due to the fine dust weathering (Frontasyeva, 510 2011).

511 The pollution load index PLI was calculated for soil and tree species. The results of soil 512 samples show that the locations namely; 25, 21, 20, 9, 30, 27, 29, 16, and 22 are slightly higher 513 than unity and classified as polluted regions. Whereas the tree species show that PLI in almost all 514 the studied samples are higher than unity. Among all samples, location numbers 27, 7, 4, 18, 16, 5152,22 , and 9 were observed to be considerably high and ranges from 3 to 9 . Based on the description of the investigated locations in Table 1SM, in the case of soil, PLI is significantly higher in MG than in GC. Contrariwise, in case of plants, except two locations 27 and 22 (train station and brick kilns), respectively. It could be explained by the densely populated, traffic, and high ways in GC, which in turn, results in elevated concentration of elements in the air rather than in MG.

Also, for a better understanding of the local situation for the soil in the investigated areas, the concentration of potentially toxic elements in soil, namely; V, Cr, Mn, $\mathrm{Co}, \mathrm{Ni}, \mathrm{Zn}, \mathrm{As}, \mathrm{Sb}, \mathrm{Ba}$ (average values for Cairo and Menoufia) were compared with the corresponding alert/intervention values in different countries worldwide according to their State Regulatory Norms as shown in Table 4. The average PLI of the Greater Cairo and Menoufia Governorate were calculated by normalizing the average values of potential pollutants to these alert/intervention limits for different countries. It is clear from the table that, despite the significant variability of different State Regulatory Laws, the investigated soil seems to be below the alert/intervention thresholds. Based on these findings, the investigated soils do not need any further action. However, regular monitoring is highly recommended to be able to follow up on the dynamics of the concentration of these elements in the soil. 
540 Table 4: concentration $(\mathrm{mg} / \mathrm{kg})$ of potentially toxic elements in soil (average values for Cairo and

541 Menoufia) and the corresponding alert/intervention values in different countries according to their

542 State Regulatory Norms For a better understanding of the local situation, for comparison the

543 corresponding values of the average Pollution Loading Index (PLI) for the Municipality of Greater

544 Cairo and Menoufia Governorate were calculated by normalizing the average values of potential

545 pollutants to these intervention/remediation limits in all cases, the investigated soils, despite the

546 great variability of different State Regulatory Laws, seem to be below the alert/intervention

547 thresholds

548

\begin{tabular}{|c|c|c|c|c|c|c|c|c|c|}
\hline \multirow[t]{2}{*}{ Element } & \multicolumn{2}{|c|}{ Present work } & \multirow{2}{*}{$\begin{array}{l}\text { Netherl } \\
\text { ands }{ }^{1} \\
2009 \\
\end{array}$} & \multirow{2}{*}{$\begin{array}{c}\text { Australia } \\
2 \\
2010 \\
\end{array}$} & \multirow{2}{*}{$\begin{array}{c}\text { Canada } 1997^{3} \\
\text { Residential/Agricu } \\
\text { ltural } \\
\end{array}$} & \multirow{2}{*}{$\begin{array}{c}\text { Romania }^{4} \\
1997\end{array}$} & \multirow{2}{*}{$\begin{array}{l}\text { US EPA }^{5} \\
2017\end{array}$} & \multirow{2}{*}{$\begin{array}{c}\text { Russian } \\
\text { Federation }^{6} \\
1991 \\
\end{array}$} & \multirow{2}{*}{$\begin{array}{l}\text { Serbia } \\
{ }^{7} 2018\end{array}$} \\
\hline & Cairo & Menoufia & & & & & & & \\
\hline $\mathrm{V}$ & 84 & 137 & 250 & 50 & $200 / 200$ & 200 & 39 & 150 & 250 \\
\hline $\mathrm{Cr}$ & 50 & 85 & 180 & 400 & ND & 300 & 12000 & ND & 380 \\
\hline $\mathrm{Mn}$ & 472 & 1007 & ND & 500 & ND & 2500 & 180 & 1500 & ND \\
\hline $\mathrm{Co}$ & 12 & 25 & 190 & 50 & $50 / 2$ & 50 & 23 & ND & 240 \\
\hline $\mathrm{Ni}$ & 32 & 52 & 100 & 60 & $100 / 150$ & 150 & 84 & 85 & 210 \\
\hline $\mathrm{Zn}$ & 170 & 70 & 720 & 20 & ND & 600 & 2300 & 100 & 720 \\
\hline As & 3 & 4 & 76 & 20 & ND & 25 & 068 & 2 & 55 \\
\hline $\mathrm{Sb}$ & 2 & 2 & 22 & ND & $20 / 20$ & 20 & 31 & 45 & 15 \\
\hline \multirow[t]{3}{*}{$\mathrm{Ba}$} & 374 & 206 & 920 & 300 & ND & 625 & 1500 & ND & 625 \\
\hline & Cairo & --- & 017 & 067 & $024 / 048$ & 022 & 051 & 065 & 016 \\
\hline & --- & Menoufia & 019 & 084 & 037/074 & 027 & 063 & 078 & 018 \\
\hline
\end{tabular}

549

$550{ }^{1}$ (ESdat, 2013)

$551{ }^{2}$ (Department for Environment and Conservation, 2010)

$552{ }^{3}$ (ESdat, 1997)

5534 (Ministry of Waters Forests and Environmental Protection, 1997)

554 (US EPA, 2017)

$555{ }^{6}$ (Russian Federal Service for Supervision of Consumer Rights Protection and Human Welfare,

556 2006)

$557{ }^{7}$ (National Regulation of Republic of Serbia, 2018)

558

559

560 


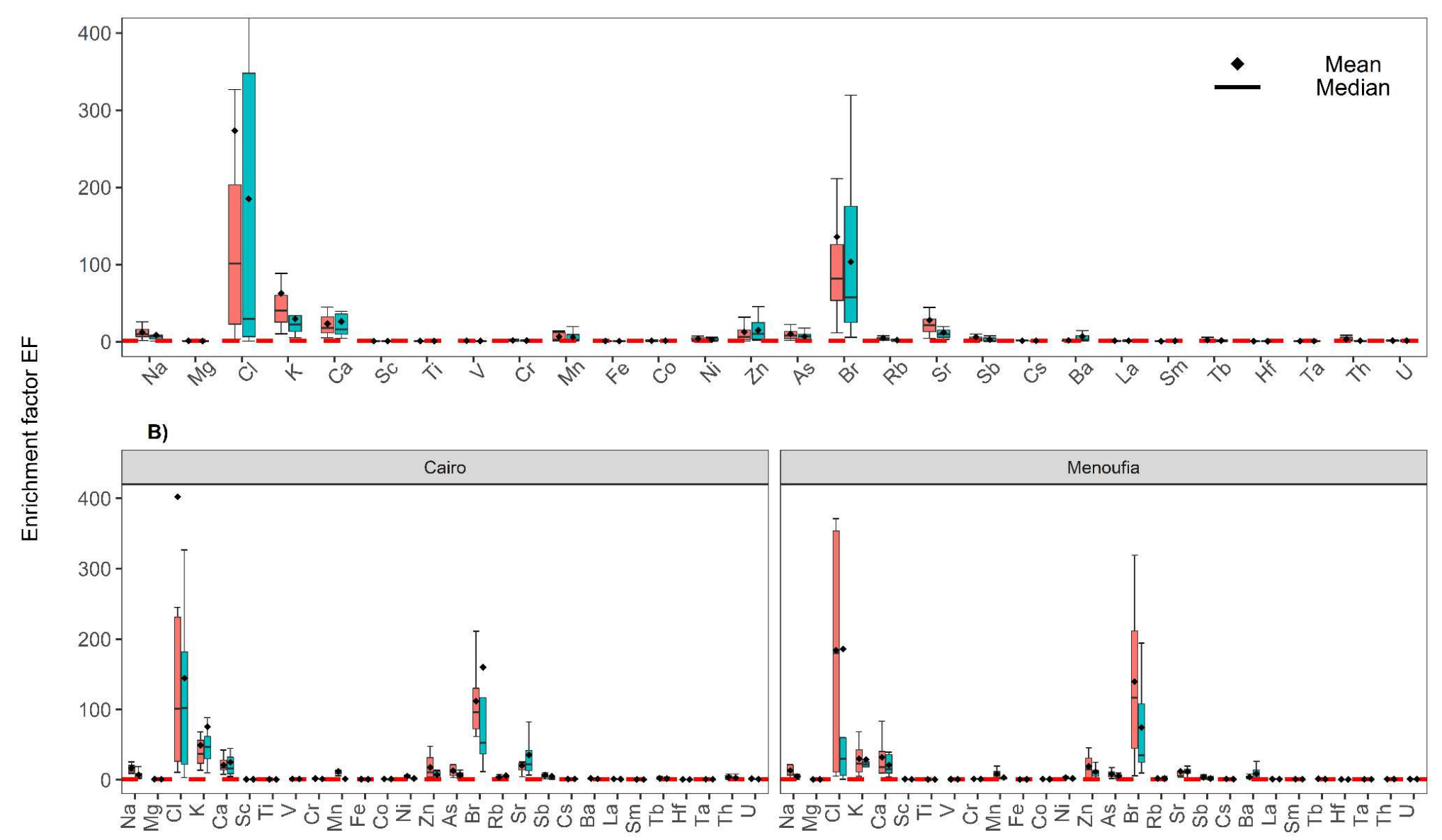


Another powerful index is widely used to assess ecological risk is the potential ecological

564 risk index PER. PER was calculated for selected elements in the studied soil and tree species

565 samples. Specifically, the selected elements are Ni, Cr, Zn, and As in soil. While in tree species,

$566 \mathrm{Cr}, \mathrm{Ni}, \mathrm{Cu}, \mathrm{Zn}, \mathrm{As}$, and $\mathrm{Cd}$ were used. These elements were selected because their epidemiological

567 data are available and given by (Hakanson, 1980; Karuppasamy et al., 2017).

568 PER was assessed, and the results are illustrated in Fig. 7. Based on the interpretation

569 criteria for PER and risk index RI that are given in Table 3SM and Fig. 7 a) for the soil it can be

570 concluded that there is a low PER as the calculated PER is less than 40. Whereas, in tree species

571 the calculated PER for As and Cd are considerably high, and this may pose a significant hazard to

572 the environment and hence to the humans.

573 The risk index RI was calculated, and according to the interpretation criteria in Table 3SM,

574 the locations namely $19,7,26,18,4,27,23$, and 10 are classified as considerable potential

575 ecological risk locations, and 9, 28, 24, 5, 8, 6, 2, 21, 29, 16, 22, 1, 3, and 30 are moderate potential

576 ecological risk locations. In comparison, the rest are low RI. 


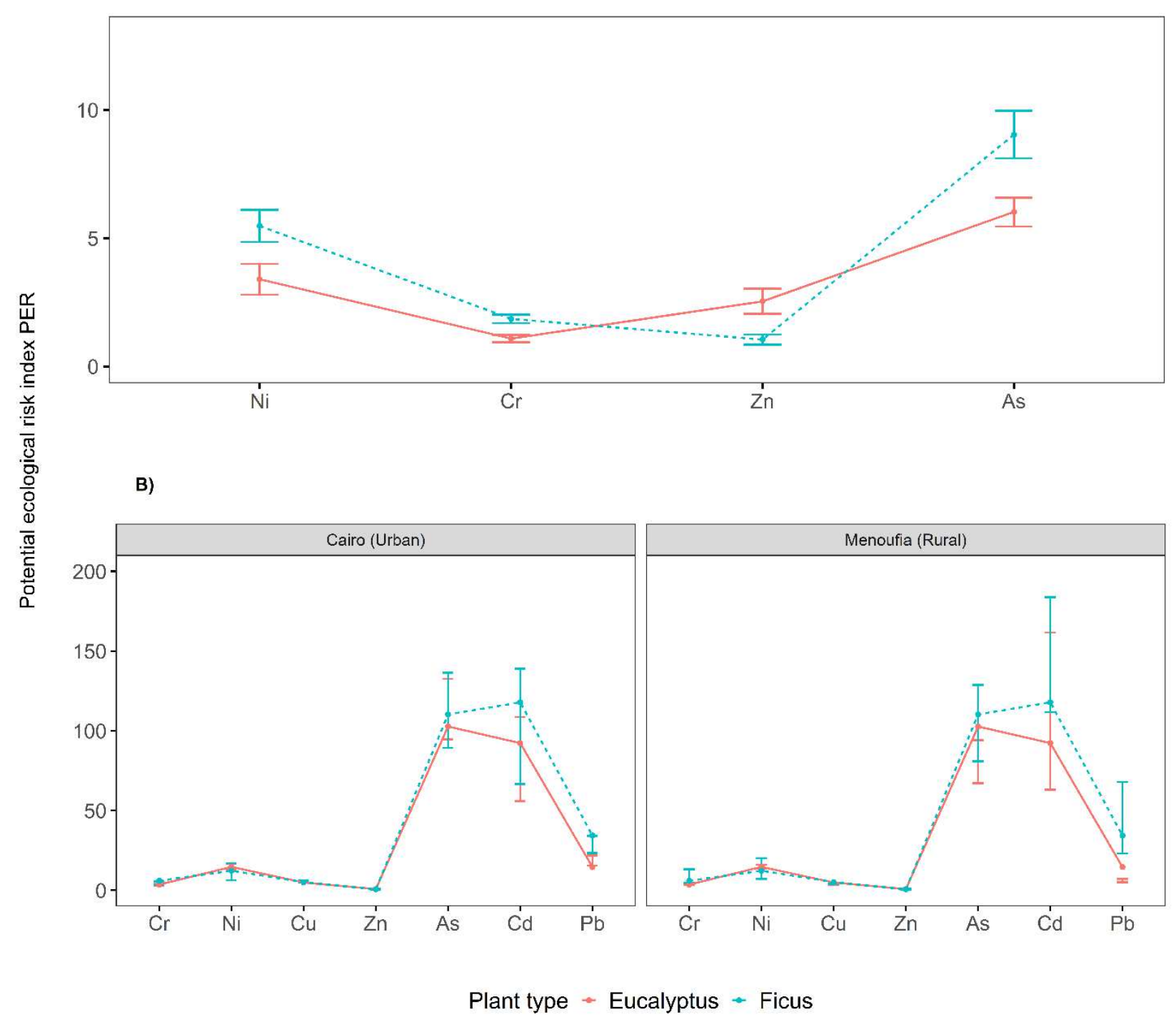

Fig. 7: Potential ecological risk index of selected elements from the examined soil and vegetation samples

\section{Findings of human toxicity and terrestrial ecotoxicity}

581 Human toxicity and terrestrial ecotoxicity were quantified using the ReCiPe method and 582 characterization factors. Human toxicity and terrestrial ecotoxicity, expressed in mg 1,4583 dichlorobenzeneequivalents (1,4 DCB-eq), are used as a midpoint characterization factor. As 584 shown in figure 8 and figure 9, in the result of the human toxicity, which considered soil and

585 vegetation results, the human toxicity impacts in most urban locations (average 3.7E+07) are much 586 higher than in rural locations (average 7.8E+06). The location 07 (1.1E+08), 04 (6.3E+07), 05 587 (5.9E+07), $01(4.4 \mathrm{E}+07), 20(4.4 \mathrm{E}+07)$, and $06(3.6 \mathrm{E}+07)$ showed high human toxicity results. In 
588 the terrestrial ecotoxicity aspect, the results of rural locations (average 2.9E+05) are much higher 589 than the results in urban locations (average 1.9E+05).

590
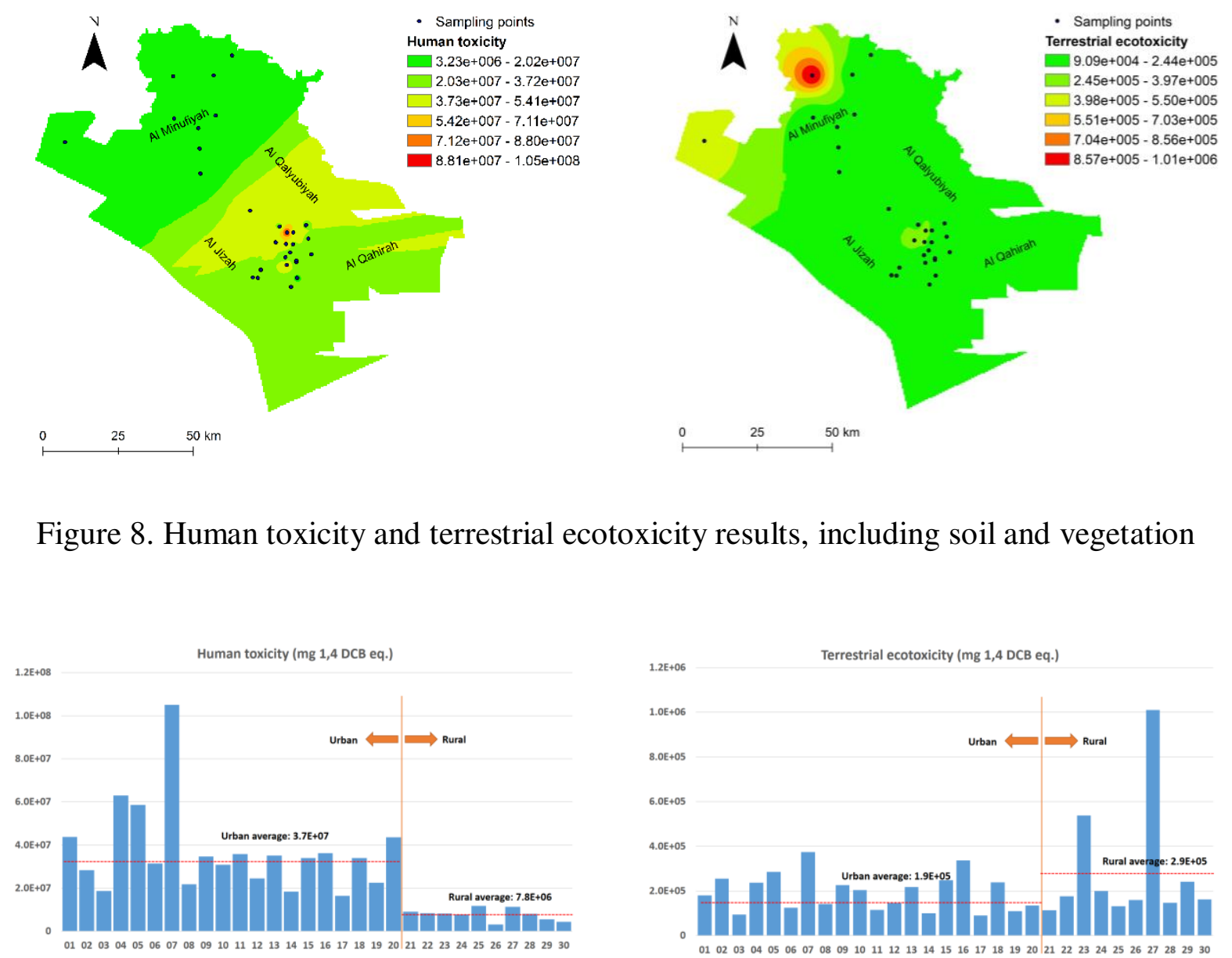

Figure 9. Human toxicity and terrestrial ecotoxicity results in urban and rural locations

595 To be more specific, in the results of urban vegetation locations, mostly $\mathrm{Ba}$ (on average, $27 \%$ ), $\mathrm{Cl}$ 596 (on average, 26\%), $\mathrm{Al}$ (on average, 21\%), Se (on average, 16\%), and As (on average, 10\%) 597 elements effect to the human toxicity. In the results of rural vegetation locations, mostly $\mathrm{Cl}$ (on 598 average, 37\%), Se (on average, 26\%), As (on average, 20\%), Al (on average, 16\%), and Cd (on 599 average, 1\%) elements effect to the human toxicity. In the results of terrestrial ecotoxicity, $\mathrm{Al}$ (on 600 average, 98\%) and $\mathrm{Cl}$ (on average, 2\%) element effect mostly in urban and rural vegetation 601 locations.

602 In the results of urban soil locations, mostly Ba (on average, 73\%), Mn (on average, 20\%), V (on 603 average, 4\%), and As (on average, 3\%) elements effect to the human toxicity. In the results of rural 604 soil locations, similarly, like the results of urban soil locations, Ba (on average, 83\%), V (on 605 average, 6\%), $\mathrm{Mn}$ (on average, 5\%), and $\mathrm{Zn}$ (on average, 3\%) showed high contributions to the 606 human toxicity. In the results of urban soil locations, $\mathrm{Zn}$ (on average, 48\%), V (on average, 26\%), 
$607 \mathrm{Ni}$ (on average, 13\%), and Ag (on average, 7\%) elements effect to the terrestrial ecotoxicity. In

608 the results of rural soil locations, V (on average, 49\%), Ag (on average, 25\%), Co (on average, $6097 \%$ ), $\mathrm{Br}$ (on average, 7\%), and $\mathrm{Ni}$ (on average, 5\%) showed high contributions to the terrestrial 610 ecotoxicity. (for more detailed human toxicity and terrestrial ecotoxicity information of each 611 element, please see figure 5SM in Supplementary Material)

612

\section{Conclusions}

614

615 The present work achieved its main objectives of determining the elemental composition and 616 quantifying the air quality in terms of metal content and associated human and terrestrial toxicity 617 impact. The normalized accumulated metals in tree leaves show that $F$. benjamina is slightly 618 higher than in E. globulus in GC and MG. In terms of the investigated areas, the concentrations of 619 metals in MG are considerably higher than those in GC. Despite the densely populated and traffic 620 in GC, the adjacent soil samples' analysis shows that the concentrations of the elements in MG are 621 significantly higher than in GC. The concentrations of $\mathrm{Cl}, \mathrm{Br}, \mathrm{Sb}, \mathrm{Ti}$, and $\mathrm{Fe}$ were noticed to be 622 higher than those in the corresponding values for UCC. PCA partitioned the obtained elements 623 into four groups of geogenic provenance and anthropogenic ones. The main contribution of the 624 anthropogenic impact comes from el Darb el Ahmr, Cairo Thermal Power Plant in Shubra El625 kheima, al-Amireyya (densely populated areas), and El-sayyeda Zainab in GC. While in MG 626 comes mainly from Al shuhadaa City near MG adjacent to the central Railroad station, Sadat City 627 (industrial zone). DA analysis reveals that there is a considerable crustal association to the 628 accumulated concentrations. It is highly recommended to remove out the crustal association prior 629 to the calculation of enrichment factor to avoid the overestimation and misleading of the results. 630 These data may be used as basic guidelines by regulatory bodies in Egypt to control the inorganic 631 metal emission in the atmosphere. In addition, planting these trees would be of high importance in 632 inorganic metal air polluted areas.

633

634 635

636 The authors acknowledge the joint project \#405 between the Academy of scientific research and 637 technology (Egypt) and Joint Institute for Nuclear Research (Dubna - Russia) ASRT-JINR 638 collaboration. 


\section{References}

Acosta, J.A., Gabarrón, M., Faz, A., Martínez-Martínez, S., Zornoza, R., Arocena, J.M., 2015. Influence of population density on the concentration and speciation of metals in the soil and street dust from urban areas. Chemosphere 134, 328-337, https://doi.org/10.1016/j.chemosphere.2015.04.038.

645 Al-Khashman, O.A., Al-Muhtaseb, A.a.H., Ibrahim, K.A., 2011. Date palm (Phoenix dactylifera L.) leaves as biomonitors of atmospheric metal pollution in arid and semi-arid environments. Environmental Pollution 159, 1635-1640, https://doi.org/10.1016/j.envpol.2011.02.045. Badawy, W.M., El-Taher, A., Frontasyeva, M.V., Madkour, H.A., Khater, A.E.M., 2018. Assessment of anthropogenic and geogenic impacts on marine sediments along the coastal areas of Egyptian Red Sea. Applied Radiation and Isotopes 140, 314-326, https://doi.org/10.1016/j.apradiso.2018.07.034. Bargagli, R., 1989. Determination of metal deposition patterns by epiphytic lichens. Toxicological \& Environmental Chemistry 18, 249-256, 10.1080/02772248909357318.

Bargagli, R., Brown, D.H., Nelli, L., 1995. Metal biomonitoring with mosses: Procedures for correcting for soil contamination. Environmental Pollution 89, 169-175, https://doi.org/10.1016/0269-7491(94)00055$\underline{1 .}$

Brunekreef, B., Holgate, S.T., 2002. Air pollution and health. The Lancet 360, 1233-1242, https://doi.org/10.1016/S0140-6736(02)11274-8.

CAPMS, 2019. Egypt in figures, Central Agency for Public Mobilization and Statistics, Egypt.

Chaligava, O., Shetekauri, S., Badawy, W.M., Frontasyeva, M.V., Zinicovscaia, I., Shetekauri, T., Kvlividze, A., Vergel, K., Yushin, N., 2020. Characterization of Trace Elements in Atmospheric Deposition Studied by Moss Biomonitoring in Georgia. Archives of Environmental Contamination and Toxicology, 10.1007/s00244-020-00788-x.

Christensen, E.R., Steinnes, E., Eggen, O.A., 2018. Anthropogenic and geogenic mass input of trace elements to moss and natural surface soil in Norway. Science of The Total Environment 613-614, 371-378, https://doi.org/10.1016/j.scitotenv.2017.09.094.

Csima, P., 2010. Urban Development and Anthropogenic Geomorphology, in: Szabó, J., Dávid, L., Lóczy, D. (Eds.), Anthropogenic Geomorphology: A Guide to Man-Made Landforms. Springer Netherlands, Dordrecht, pp. 179-187, 10.1007/978-90-481-3058-0_12.

669 De Schryver A, Goedkoop M, 2009. ReCiPe 2008: A life cycle impact assessment method which comprises harmonised category indicators at the midpoint and the endpoint level. Report I: Characterisation factors, in: M Goedkoop, R.H., MAJ Huijbregts, A De Schryver, J Struijs and R van Zelm. (Ed.), Ruimte Enmilieu, Ministerie Van Volkshuisvesting, Tuimtelijke Ordening en Milieubeheer, 1st ed.

673 Dekker, E., Zijp, M.C., van de Kamp, M.E., Temme, E.H.M., van Zelm, R., 2019. A taste of the new ReCiPe for life cycle assessment: consequences of the updated impact assessment method on food product LCAs. The International Journal of Life Cycle Assessment, 10.1007/s11367-019-01653-3.

676 Department for Environment and Conservation, 2010. Environmental Guidelines and Standards of Australia. .Contaminated Sites Management Series: Assessment levels for Soil, Sediment and Water. El-Khatib, A.A., Barakat, N.A., Youssef, N.A., Samir, N.A., 2020. Bioaccumulation of heavy metals air pollutants by urban trees. International Journal of Phytoremediation 22, 210-222, 10.1080/15226514.2019.1652883.

ESdat, 1997. Canadian Environmental Guidelines and Standards. Environmental Management Act: CONTAMINATED SITES REGULATION.

ESdat, 2013. Dutch target and intervention values, 2000 (the New Dutch list). VROM: Former Ministry of Housing, Spatial Planning and the Environment (presently Ministry Infrastructure and the Environment.

Faith, M., 2015. Centered Log-Ratio (clr) Transformation and Robust Principal Component Analysis of Long-Term NDVI Data Reveal Vegetation Activity Linked to Climate Processes. Climate 3, 135, doi:10.3390/cli3010135.

Farahat, E.A., 2011. Biomonitoring of Airborne Heavy Metals Pollution by Delonix regia (Boj. ex Hook.) Raf. in Greater Cairo, Egypt. Taeckholmia 31, 1-15.

690 Fife, D.N., Nambiar, E.K.S., Saur, E., 2008. Retranslocation of foliar nutrients in evergreen tree species

691 planted in a Mediterranean environment. Tree Physiology 28, 187-196, 10.1093/treephys/28.2.187. 
Freer-Smith, P.H., El-Khatib, A.A., Taylor, G., 2004. Capture of Particulate Pollution by Trees: A Comparison of Species Typical of Semi-Arid Areas (Ficus Nitida and Eucalyptus Globulus) with European and North American Species. Water, Air, and Soil Pollution 155, 173-187, 10.1023/B:WATE.0000026521.99552.fd. Frontasyeva, M., Pavlov, S.S., 2005. Scientific reviews: radioanalytical investigations at the IBR-2 reactor in Dubna. Neutron News 16, 24-27, 10.1080/10448630500454387.

697 Frontasyeva, M.V., 2011. Neutron activation analysis in the life sciences. Physics of Particles and Nuclei 698 42, 332-378, 10.1134/S1063779611020043.

699 Gall, J.E., Boyd, R.S., Rajakaruna, N., 2015. Transfer of heavy metals through terrestrial food webs: a 700 review. Environmental Monitoring and Assessment 187, 201, 10.1007/s10661-015-4436-3.

701 Goedkoop, M., Spriensma, R., 2001. The Eco-Indicator 99: A Damage Oriented Method for Life Cycle 702 Impact Assessment.

703 Gorelova, S.V., Frontasyeva, M.V., 2017. The Use of Higher Plants in Biomonitoring and Environmental 704 Bioremediation, in: Ansari, A.A., Gill, S.S., Gill, R., R. Lanza, G., Newman, L. (Eds.), Phytoremediation: Management of Environmental Contaminants, Volume 5. Springer International Publishing, Cham, pp. 103-155, 10.1007/978-3-319-52381-1_5.

Hakanson, L., 1980. An ecological risk index for aquatic pollution control.a sedimentological approach. Water Research 14, 975-1001, https://doi.org/10.1016/0043-1354(80)90143-8.

Hallinan, J.S., 2012. Chapter 2 - Data mining for microbiologists, in: Harwood, C., Wipat, A. (Eds.), Methods in Microbiology. Academic Press, pp. 27-79, https://doi.org/10.1016/B978-0-08-099387-4.00002-8.

Hassanien, M.A., 2011. Atmospheric heavy metals pollution: exposure and prevention policies in Mediterranean basin, Springer, Dordrecht.

Huijbregts M.A.J., Van Zelm R, 2009. Ecotoxicity and human toxicity. Chapter 7. In ReCiPe 2008 A life cycle impact assessment method which comprises harmonised category indicators at the midpoint and the endpoint level. Report I: Characterisation factors., 1st ed.

Jiang, Y., Fan, M., Hu, R., Zhao, J., Wu, Y., 2018. Mosses Are Better than Leaves of Vascular Plants in Monitoring Atmospheric Heavy Metal Pollution in Urban Areas. Int J Environ Res Public Health 15, 1105, 10.3390/ijerph15061105.

Kabata-Pendias, A., 2011. Trace elements in soils and plants. CRC Press, 1-534, 10.1201/b10158-25.

Kampa, M., Castanas, E., 2008. Human health effects of air pollution. Environmental Pollution 151, $362-$ 367, https://doi.org/10.1016/i.envpol.2007.06.012.

Karuppasamy, M.P., Qurban, M.A., Krishnakumar, P.K., Mushir, S.A., Abuzaid, N., 2017. Evaluation of toxic elements $\mathrm{As}, \mathrm{Cd}, \mathrm{Cr}, \mathrm{Cu}, \mathrm{Ni}, \mathrm{Pb}$ and $\mathrm{Zn}$ in the surficial sediments of the Red Sea (Saudi Arabia). Marine Pollution Bulletin 119, 181-190, https://doi.org/10.1016/i.marpolbul.2017.04.019.

Kowalska, J.B., Mazurek, R., Gąsiorek, M., Zaleski, T., 2018. Pollution indices as useful tools for the comprehensive evaluation of the degree of soil contamination-A review. Environmental Geochemistry and Health 40, 2395-2420, 10.1007/s10653-018-0106-z.

Madadzada, A.I., Badawy, W.M., Hajiyeva, S.R., Veliyeva, Z.T., Hajiyev, O.B., Shvetsova, M.S., Frontasyeva, M.V., 2019. Assessment of atmospheric deposition of major and trace elements using neutron activation analysis and GIS technology: Baku - Azerbaijan. Microchemical Journal 147, 605-614, https://doi.org/10.1016/i.microc.2019.03.061.

Markert, B., 1992. Establishing of reference plant for inorganic characterization of different plant-species by chemical fingerprinting. Water Air Soil Poll 64, 533-538, Doi 10.1007/Bf00483363.

Ministry of Waters Forests and Environmental Protection, 1997. ORDER no. 756 of 3 November 1997 for the approval of the Regulation on the assessment of environmental pollution in Romania.

Morton-Bermea, O., Hernández-Álvarez, E., González-Hernández, G., Romero, F., Lozano, R., BeramendiOrosco, L.E., 2009. Assessment of heavy metal pollution in urban topsoils from the metropolitan area of Mexico City. Journal of Geochemical Exploration 101, 218-224, https://doi.org/10.1016/j.gexplo.2008.07.002.

National Regulation of Republic of Serbia, 2018. The limit values of polluting, harmful and dangerous substances in the soil, Official Gazette of RS ", No. 30 of 20th April 2018.

Norouzi, S., Khademi, H., Faz Cano, A., Acosta, J.A., 2015. Using plane tree leaves for biomonitoring of dust borne heavy metals: A case study from Isfahan, Central Iran. Ecological Indicators 57, 64-73, https://doi.org/10.1016/i.ecolind.2015.04.011. 
Panda, L.S., Rai, P.K., 2015. Roadside Plants-Study on Eco-sustainability. LAP LAMBERT Academic Publishing, Germany.

Peterson, P.J., Girling, C.A., 1981. Other Trace metals: Effect of Heavy Metal Pollution on Plants: Effects of Trace Metals on Plant Function, in: Lepp, N.W. (Ed.). Springer Netherlands, Dordrecht, pp. 213-278, 10.1007/978-94-011-7339-1_7.

750 Quénéa, K., Andrianjara, I., Rankovic, A., Gan, E., Aubry, E., Lata, J.-C., Barot, S., Castrec-Rouelle, M., 2019. Influence of the residence time of street trees and their soils on trace element contamination in Paris (France). Environmental Science and Pollution Research 26, 9785-9795, 10.1007/s11356-019-04405-w. R Core Team, 2016. R: A language and environment for statistical computing. R Foundation for Statistical Computing, Vienna, Austria, http://www.R-project.org/.

755 Rai, P.K., 2016. Biodiversity of roadside plants and their response to air pollution in an Indo-Burma hotspot 756 region: implications for urban ecosystem restoration. Journal of Asia-Pacific Biodiversity 9, 47-55, https://doi.org/10.1016/j.japb.2015.10.011.

Rudnick, R.L., Gao, S., 2014. Composition of the continental crust A2 - Holland, Heinrich D, in: Turekian, K.K. (Ed.), Treatise on Geochemistry (Second Edition). Elsevier, Oxford, pp. 1-51, 10.1016/B978-0-08095975-7.00301-6.

Russian Federal Service for Supervision of Consumer Rights Protection and Human Welfare, 2006. Soil, cleaning of settlements, wastes production and consumption, sanitary soil protection. Maximum Permissible Concentrations (MPC) chemicals in the soil. Hygienic regulations GN 2.1.7.2041-06. Salim Akhter, M., Madany, I.M., 1993. Heavy metals in street and house dust in Bahrain. Water, Air, and Soil Pollution 66, 111-119, 10.1007/bf00477063. ACTIVATION ANALYSIS TO PROBE THE AIR POLLUTION USING PLANT BIOMONITORING IN EGYPT, RAP Conference Proceedings, pp. 125-130.

Shah, M.H., Ilyas, A., Akhter, G., Bashir, A., 2019. Pollution assessment and source apportionment of selected metals in rural (Bagh) and urban (Islamabad) farmlands, Pakistan. Environmental Earth Sciences 78, 189, 10.1007/s12665-019-8198-z.

Shifaw, E., 2018. Review of Heavy Metals Pollution in China in Agricultural and Urban Soils. Journal of Health and Pollution 8, 180607, 10.5696/2156-9614-8.18.180607.

Steinnes, E., 1995. A critical evaluation of the use of naturally growing moss to monitor the deposition of atmospheric metals. Science of The Total Environment 160-161, 243-249, https://doi.org/10.1016/00489697(95)04360-D.

777 Steinnes, E., Hanssen, J.E., Rambaek, J.P., Vogt, N.B., 1994. Atmospheric deposition of trace-elements in 778 Norway - temporal and spatial trends studied by moss analysis. Water Air Soil Poll 74, 121-140, Doi 779 10.1007/Bf01257151.

780 Steinnes, E., Rambæk, J.P., Hanssen, J.E., 1992. Large scale multi-element survey of atmospheric 781 deposition using naturally growing moss as biomonitor. Chemosphere 25, 735-752, https://doi.org/10.1016/0045-6535(92)90435-T.

Steinnes, E., Uggerud, H.T., Pfaffhuber, K.A., Berg, T., 2017. Atmospheric deposition of heavy metals in Norway. National moss survey 2015., NILU - Norwegian Institute for Air Research P.O. Box 100, 2027 Kjeller, p. 53.

Struijs, J., van Dijk, A., Slaper, H., van Wijnen, H.J., Velders, G.J.M., Chaplin, G., Huijbregts, M.A.J., 2010. Spatial- and Time-Explicit Human Damage Modeling of Ozone Depleting Substances in Life Cycle Impact Assessment. Environmental Science \& Technology 44, 204-209, 10.1021/es9017865.

Struijs J., Beusen A., van Jaarsveld H., Huijbregts M.A.J, 2009. Aquatic Eutrophication. In ReCiPe 2008, A life cycle impact assessment method which comprises harmonised category indicators at the midpoint and the endpoint level, in: M. Goedkoop, R. Heijungs, M. A. J. Huijbregts, A. De Schryver, J. Struijs, R. Van Zelm (Eds.), 1st ed.

Tomašević, M., Aničić, M., Jovanović, L., Perić-Grujić, A., Ristić, M., 2011. Deciduous tree leaves in trace elements biomonitoring: A contribution to methodology. Ecological Indicators 11, 1689-1695, https://doi.org/10.1016/j.ecolind.2011.04.017. 
Tong, S., Li, H., Wang, L., Tudi, M., Yang, L., 2020. Concentration, Spatial Distribution, Contamination Degree and Human Health Risk Assessment of Heavy Metals in Urban Soils across China between 2003 and 2019-A Systematic Review. Int J Environ Res Public Health 17, 3099, 10.3390/ijerph17093099. Ukpebor, E.E., Ukpebor, J.E., Aigbokhan, E., Goji, I., Onojeghuo, A.O., Okonkwo, A.C., 2010. Delonix regia 800 and Casuarina equisetifolia as passive biomonitors and as bioaccumulators of atmospheric trace metals. 801 J Environ Sci-China 22, 1073-1079, https://doi.org/10.1016/S1001-0742(09)60219-9.

802 US EPA, 2017. Region 9, Regional screening levels tables.

803 Varol, M., 2011. Assessment of heavy metal contamination in sediments of the Tigris River (Turkey) using 804 pollution indices and multivariate statistical techniques. Journal of Hazardous Materials 195, 355-364, 805 https://doi.org/10.1016/i.jhazmat.2011.08.051.

806 Vuković, G., Aničić Urošević, M., Škrivanj, S., Milićević, T., Dimitrijević, D., Tomašević, M., Popović, A., 807 2016. Moss bag biomonitoring of airborne toxic element decrease on a small scale: A street study in 808 Belgrade, Serbia. Science of The Total Environment 542, 394-403, 809 https://doi.org/10.1016/i.scitotenv.2015.10.091.

810 Wilson, P.J., 1993. Propagation characteristics of Eucalyptus globulus Labill. ssp. globulus stem cuttings in 811 relation to their original position in the parent shoot. Journal of Horticultural Science 68, 715-724, $81210.1080 / 00221589.1993 .11516404$.

813 Yalaltdinova, A., Kim, J., Baranovskaya, N., Rikhvanov, L., 2018. Populus nigra L. as a bioindicator of 814 atmospheric trace element pollution and potential toxic impacts on human and ecosystem. Ecological 815 Indicators 95, 974-983, https://doi.org/10.1016/j.ecolind.2017.06.021.

816 Yekeen, T.A., Xu, X., Zhang, Y., Wu, Y., Kim, S., Reponen, T., Dietrich, K.N., Ho, S.-m., Chen, A., Huo, X., 817 2016. Assessment of health risk of trace metal pollution in surface soil and road dust from e-waste 818 recycling area in China. Environmental Science and Pollution Research 23, 17511-17524, 10.1007/s11356819 016-6896-6. 


\section{Declarations}

823

824

825

826

827

828

829

830

831

832

833

834

835

836

837

838

839

840

841

842

- Ethics approval and consent to participate

Not applicable

- Consent for publication

Not applicable

- Availability of data and materials

All data generated or analysed during this study are included in this published article and its supplementary information files.

- Competing interests

The authors declare that they have no competing interests

- Funding

The authors acknowledge the joint project \#405 between the Academy of scientific research and technology (Egypt) and Joint Institute for Nuclear Research (Dubna - Russia) ASRT-JINR collaboration.

- Authors' contributions

Wael M. Badawy: Conceptualization, Methodology, Writing Original draft, Yasmin Sarhan: Visualization, Investigation, Octavian G Duliu: WritingReviewing and Editing, Junbeum Kim: Writing an original draft, Reviewing and Editing, Nikita Yushin: Writing Review \& Editing, Hussein El Samman: Writing Review \& Editing, A. Hussein: Validation, Marina V. Frontasyeva: Supervision, Alexey I. Shcheglov: Software, Validation

- Acknowledgments

The authors acknowledge the joint project \#405 between the Academy of scientific research and technology (Egypt) and Joint Institute for Nuclear Research (Dubna - Russia) ASRT-JINR collaboration. 


\section{Figures}

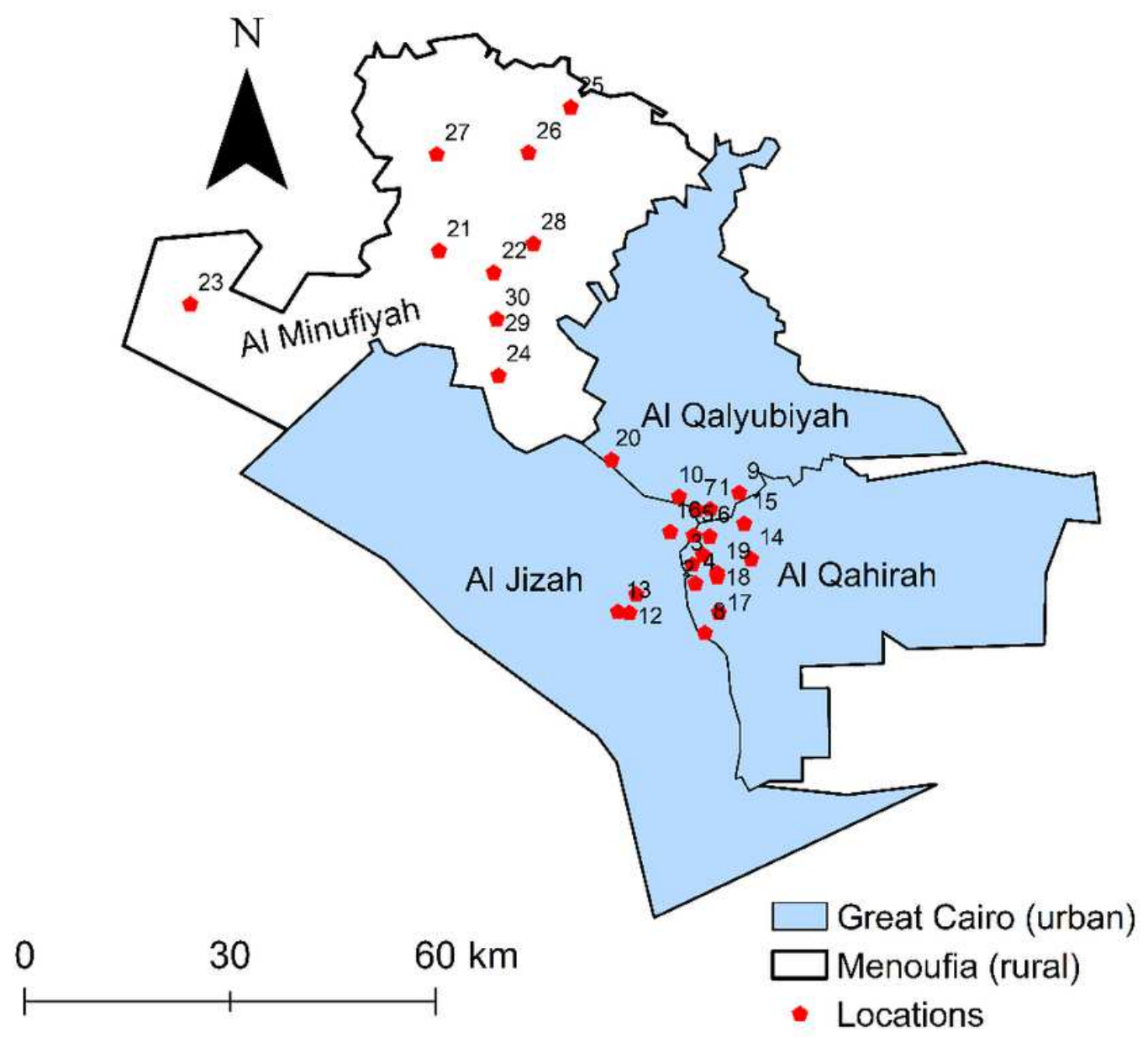

\section{Figure 1}

Map of sampling localities Note: The designations employed and the presentation of the material on this map do not imply the expression of any opinion whatsoever on the part of Research Square concerning the legal status of any country, territory, city or area or of its authorities, or concerning the delimitation of its frontiers or boundaries. This map has been provided by the authors. 


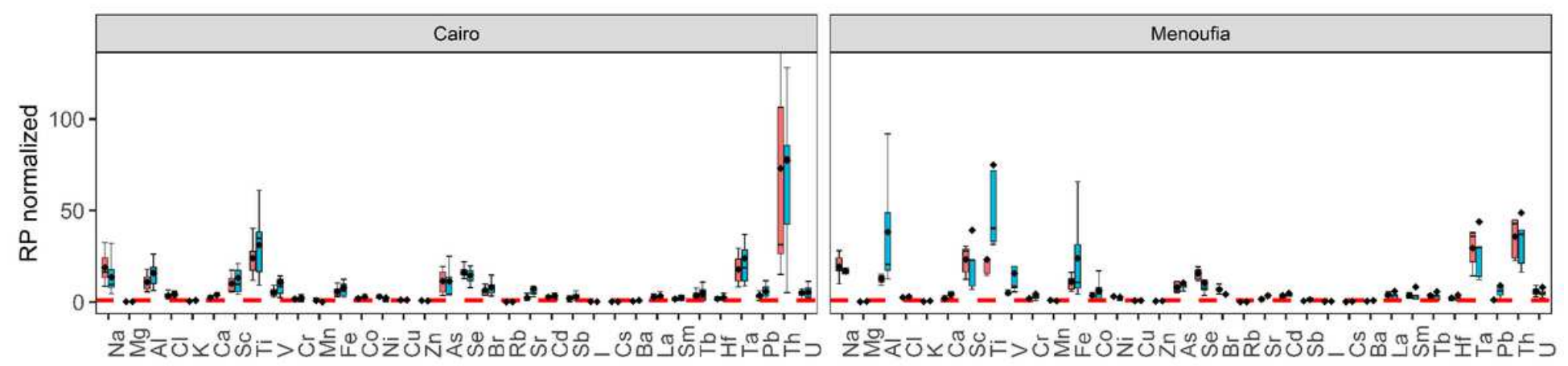

B)

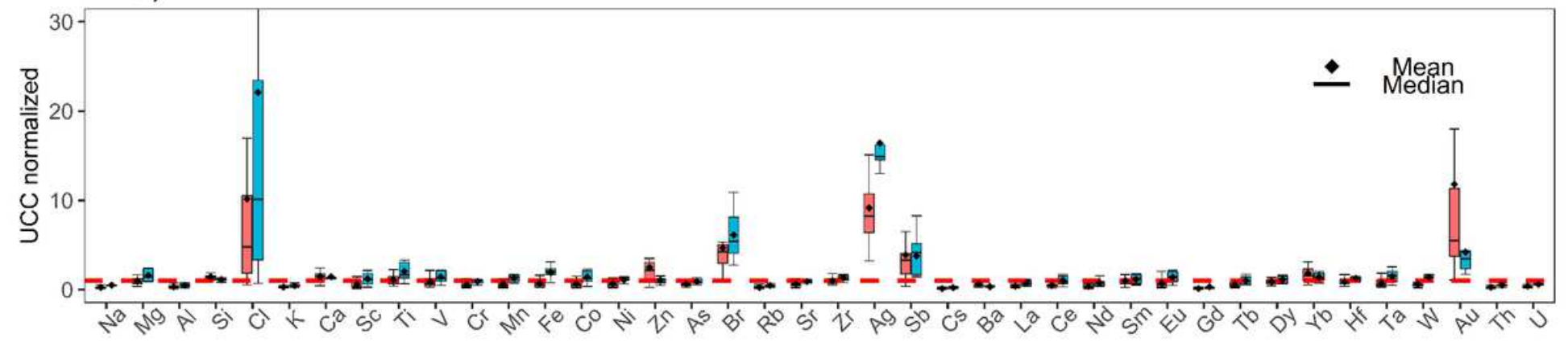

Location Cairo Menoufia

Figure 2

Box-plots illustrating the distribution of investigated elements in Cairo and Menoufia for Eucalyptus globulus and Ficus bejamina. All concentrations normalized to RP (A) and soil after normalization to UCC B). 


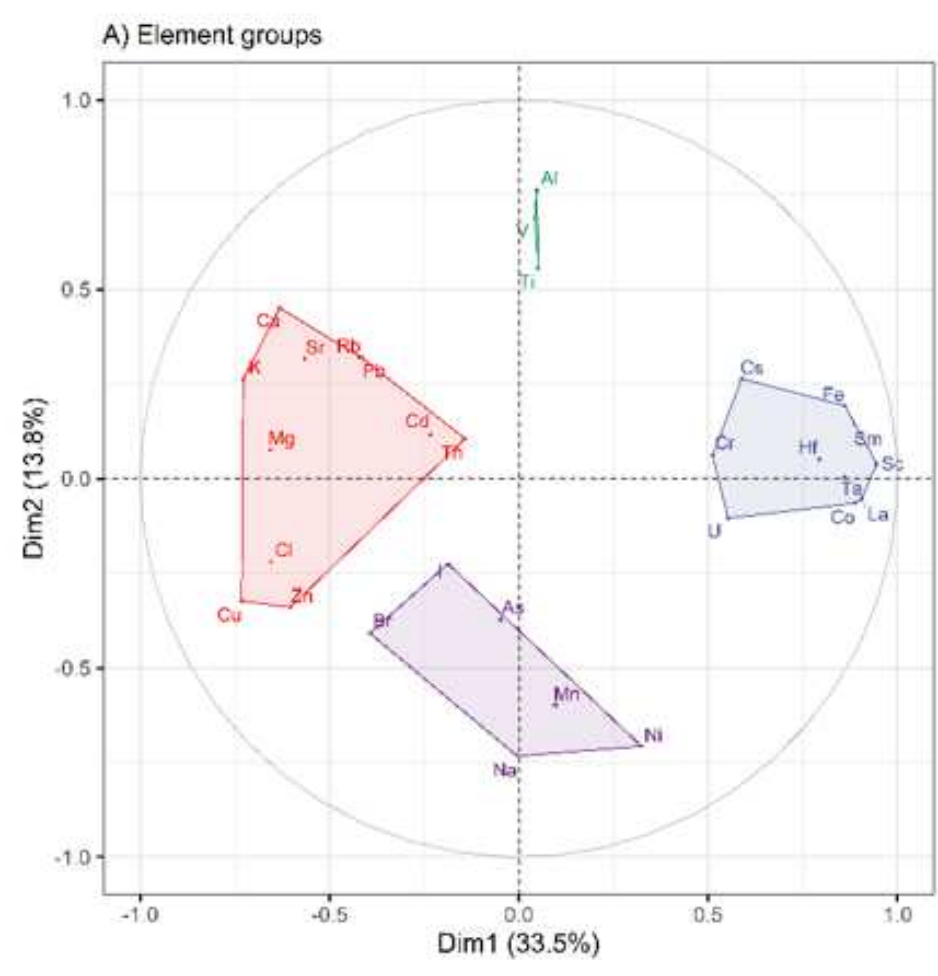

Elements groups 图 1 [ 2 图 3 国 4
B) Sampling profiles

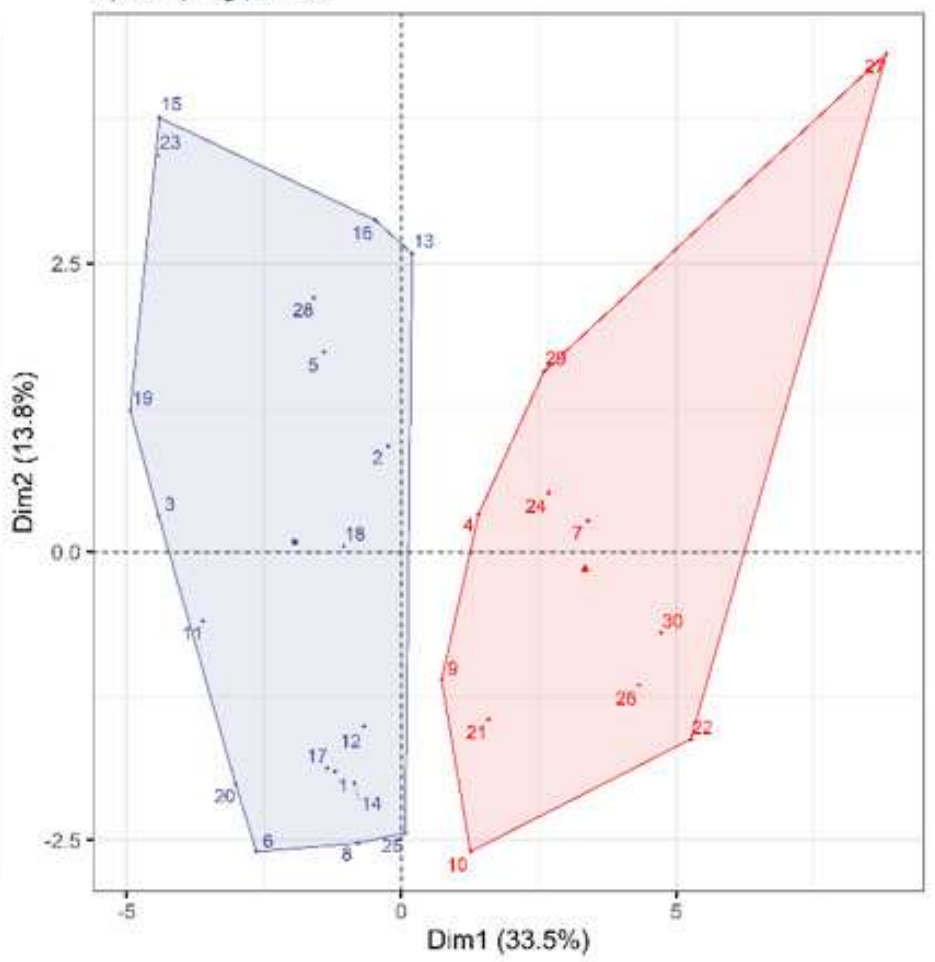

Sampling points 묘 1 망 2

\section{Figure 3}

The Principal component analysis PCA bi-plot of PC1 and PC2 for tree leaves results illustrating the existence of significant clusters of determined elements A) and investigated collecting points B).

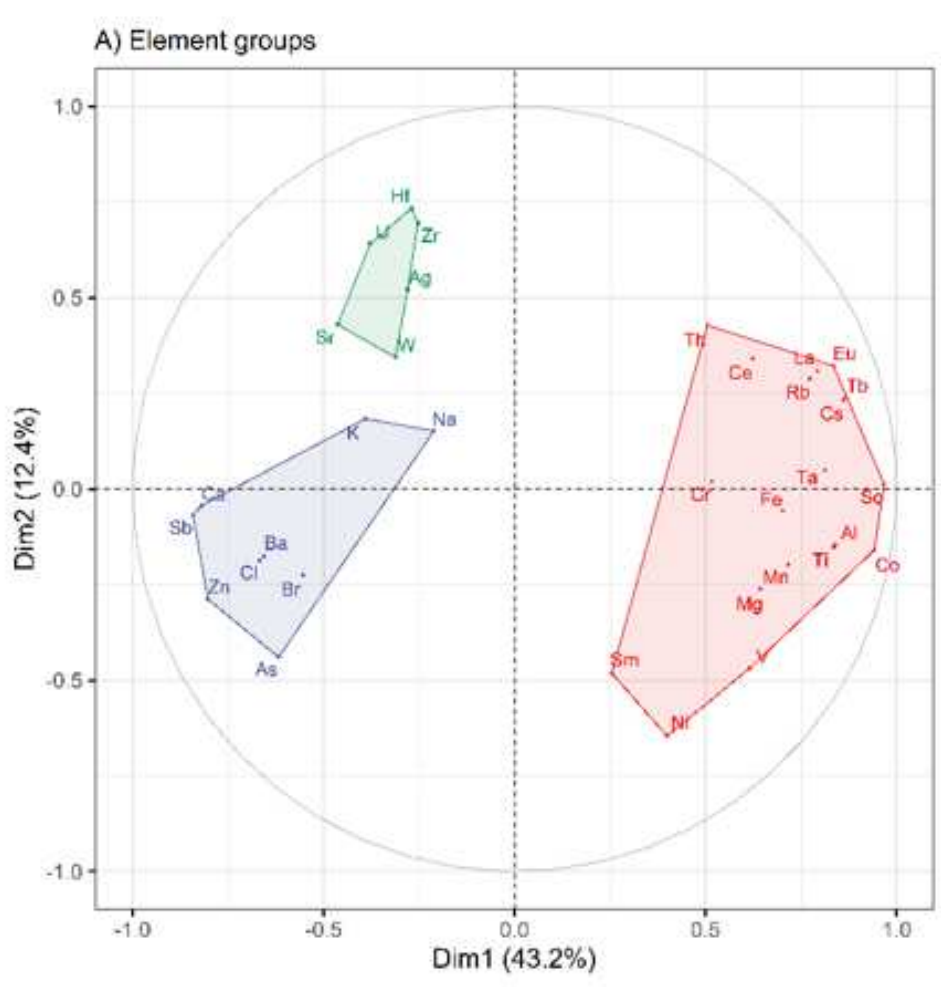

Elements groups 1 a 1 [n] 2 [a 3

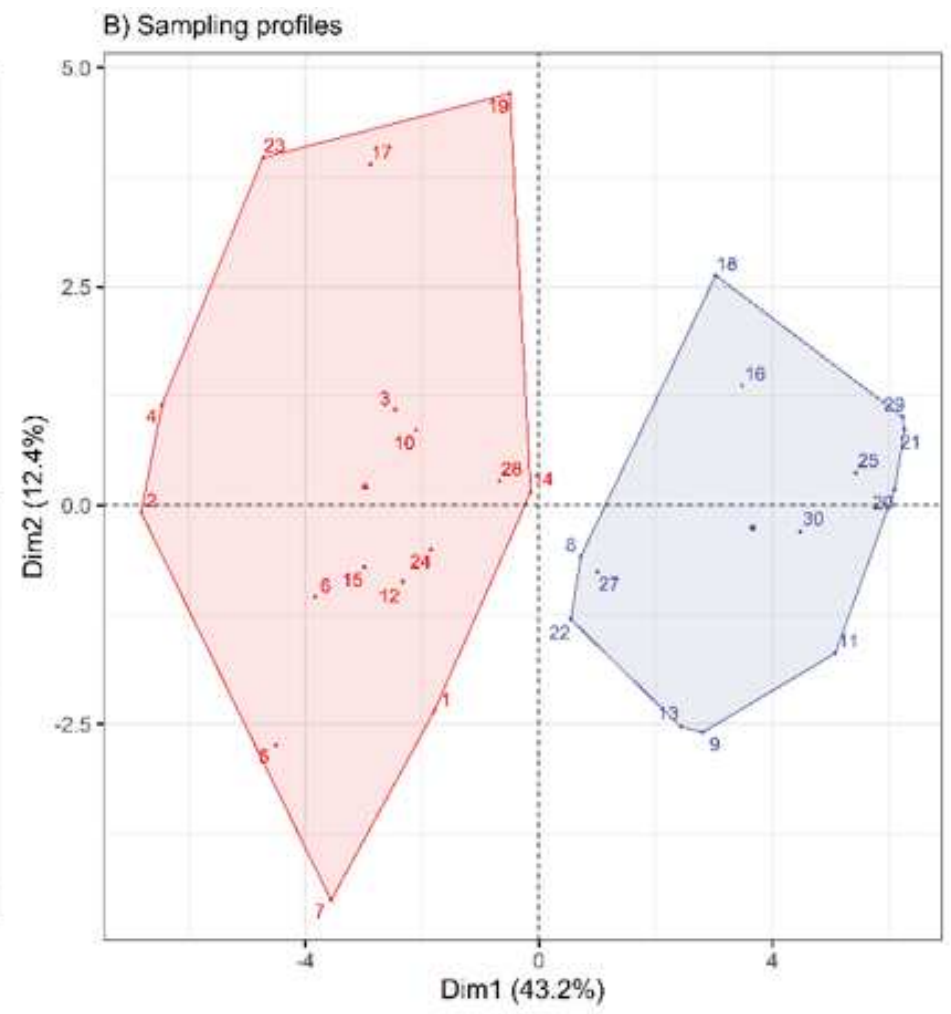

Sampling points 져 1 a 2 
Figure 4

The Principal component analysis PCA bi-plot of PC1 and PC2 for soil results illustrating the existence of significant clusters of determined elements $A$ ) and investigated collecting points $B$ ).
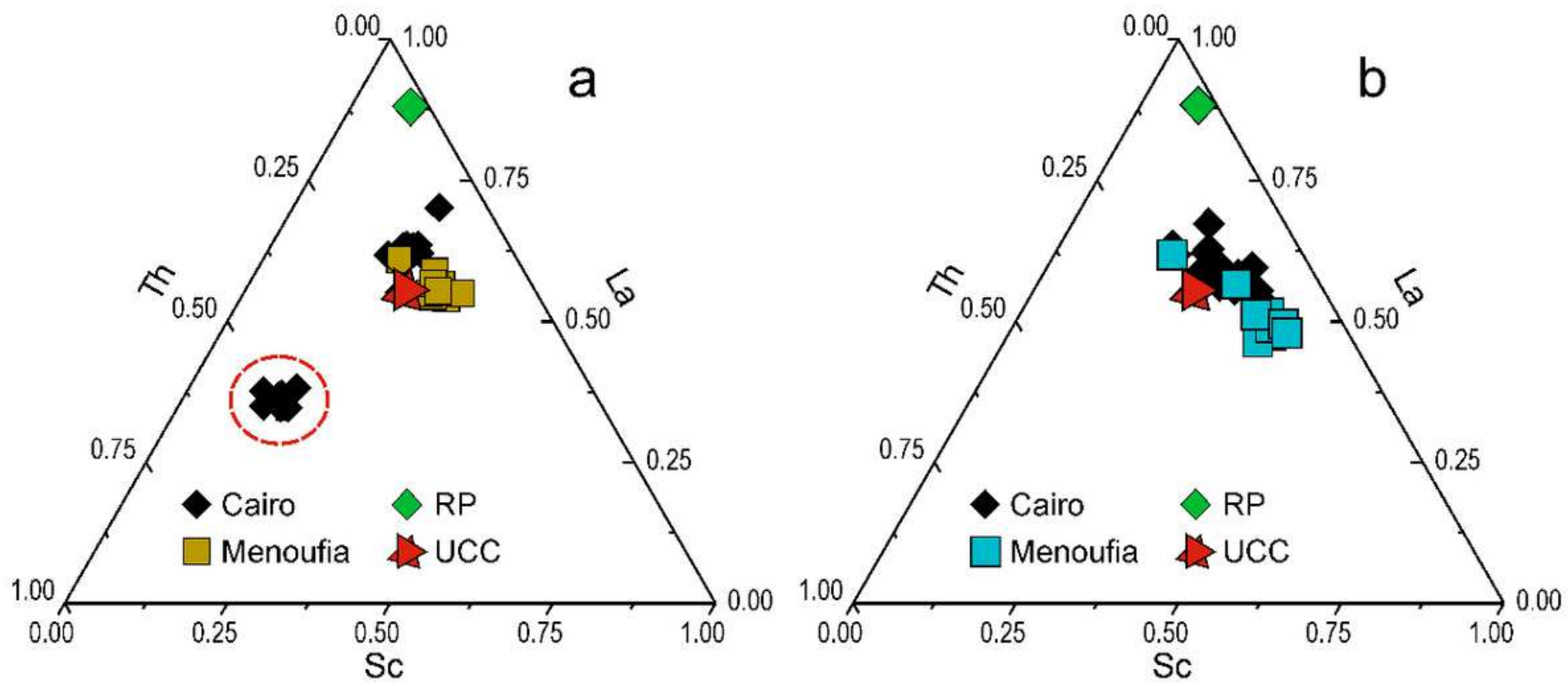

\section{Figure 5}

Sc-La-Th discriminating diagrams in the case of tree leaves (a) and soils (b). The corresponding values for reference plant RP and upper continental crust reported by Markert (1992) and Rudnick and Gao (2014), respectively were added. It is obviously that all the tree leaves points are within the vicinity of UCC, except some samples taken from one of the highest populated regions of Greater Cairo (Shubra ElKheima) and marked by a red circle on diagram (a). 


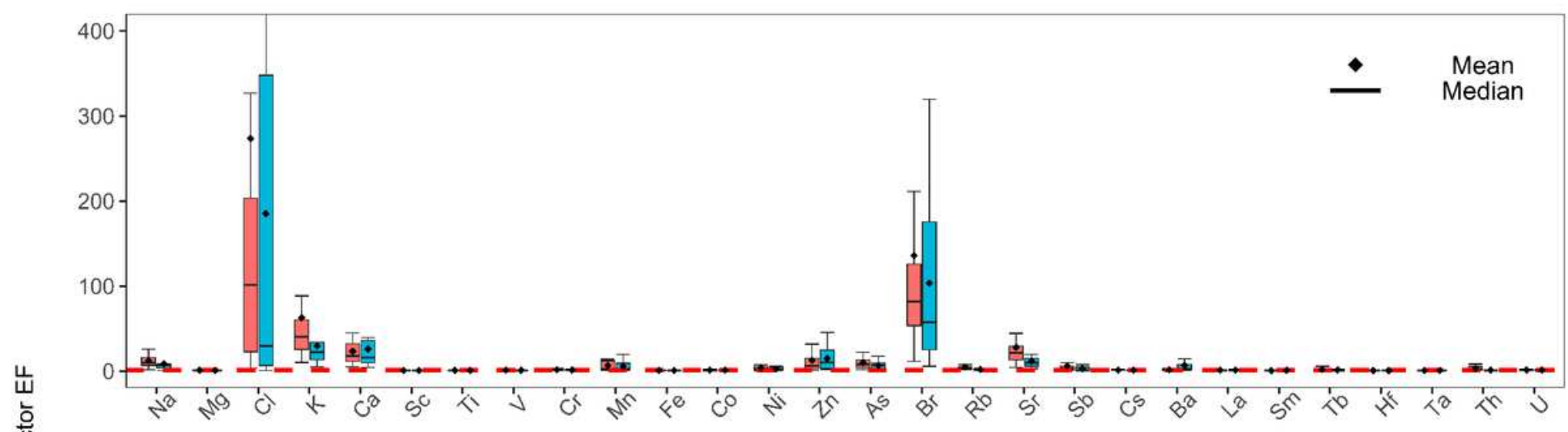

B)

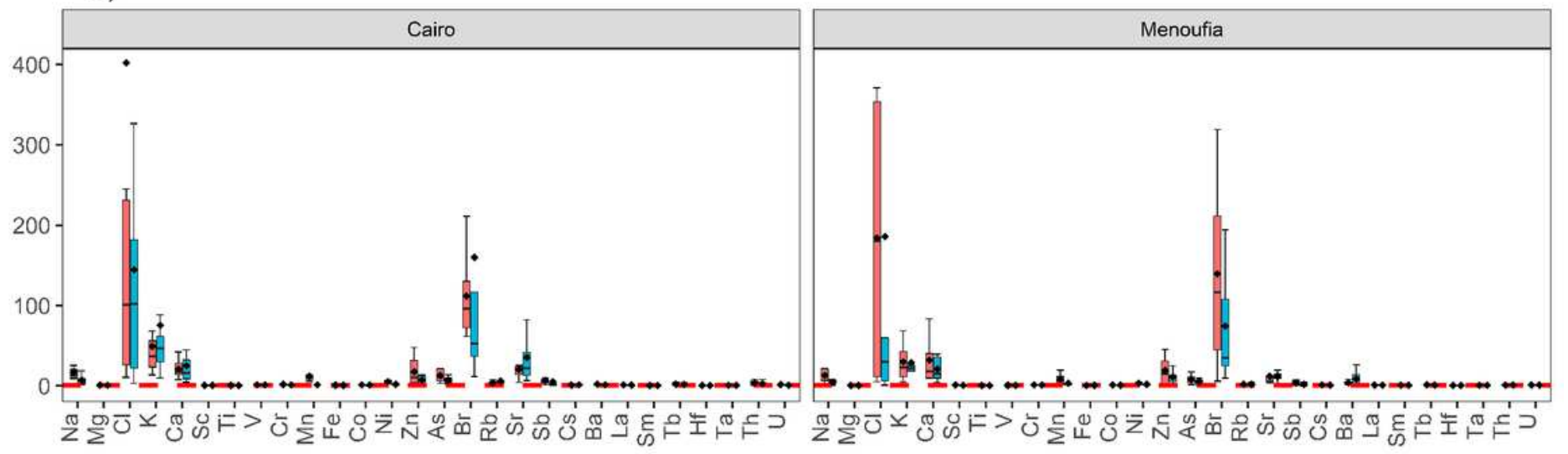

Plant type Eucalyptus Ficus

Figure 6

Boxplot illustrates of the statistics of enrichment factor EF in Cairo and Menoufia and in the two species studied 

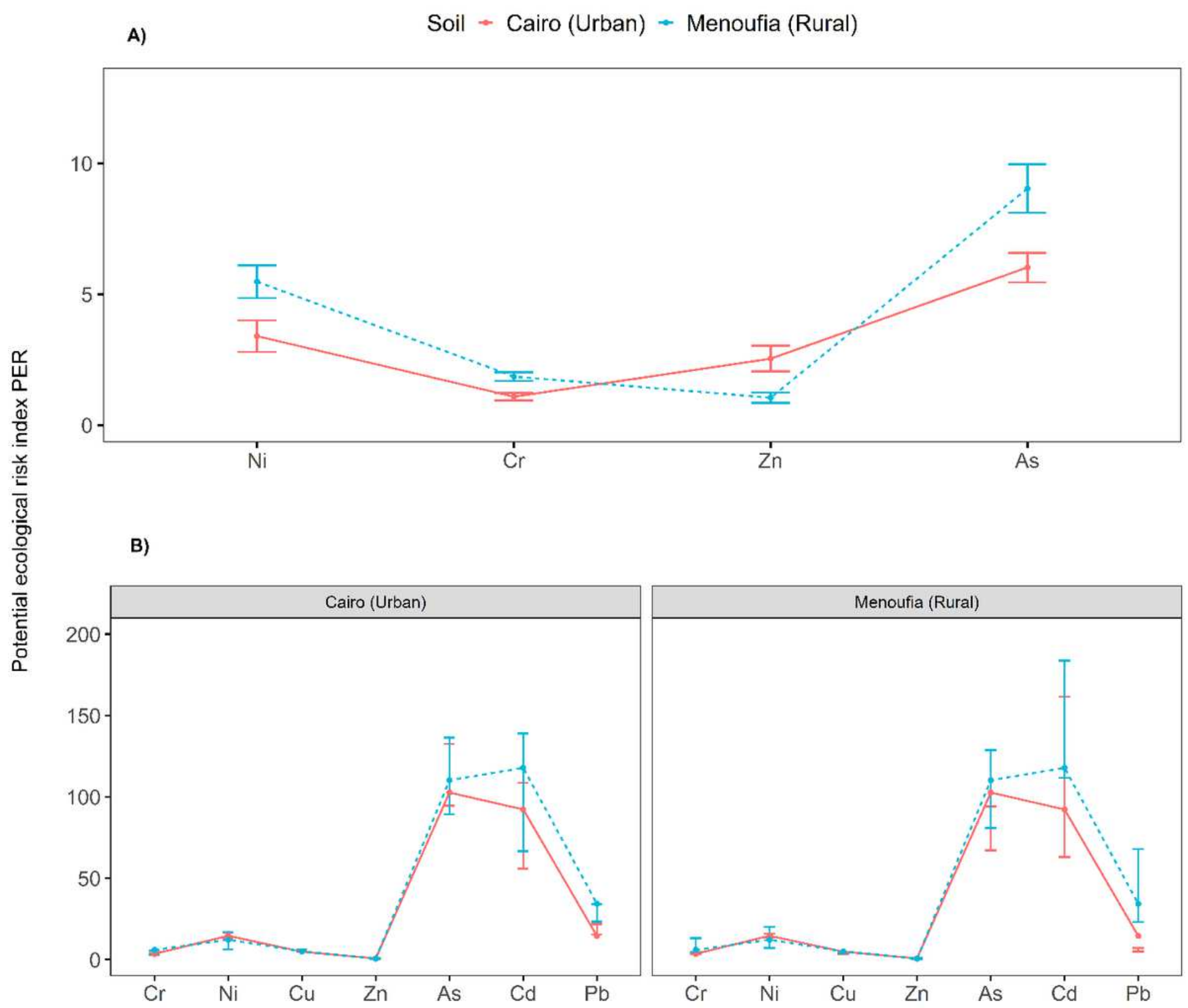

Plant type * Eucalyptus - Ficus

Figure 7

Potential ecological risk index of selected elements from the examined soil and vegetation samples 

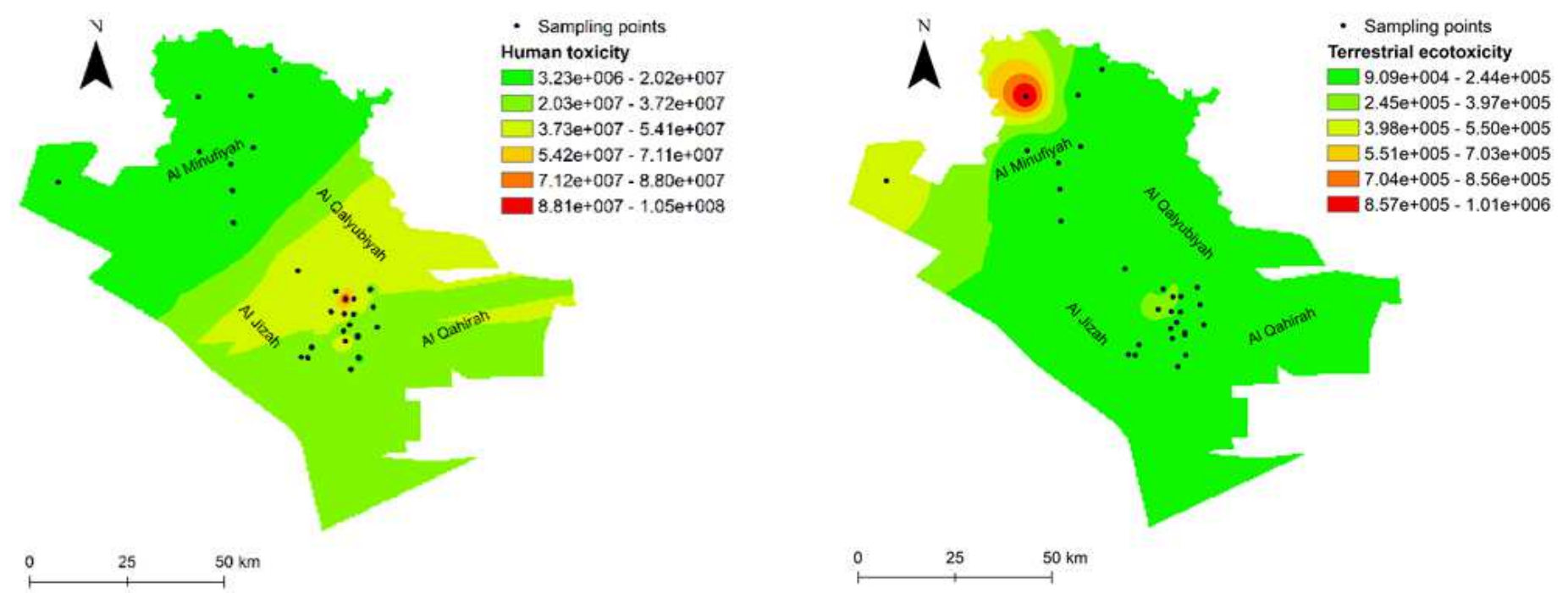

\section{Figure 8}

Human toxicity and terrestrial ecotoxicity results, including soil and vegetation Note: The designations employed and the presentation of the material on this map do not imply the expression of any opinion whatsoever on the part of Research Square concerning the legal status of any country, territory, city or area or of its authorities, or concerning the delimitation of its frontiers or boundaries. This map has been provided by the authors.
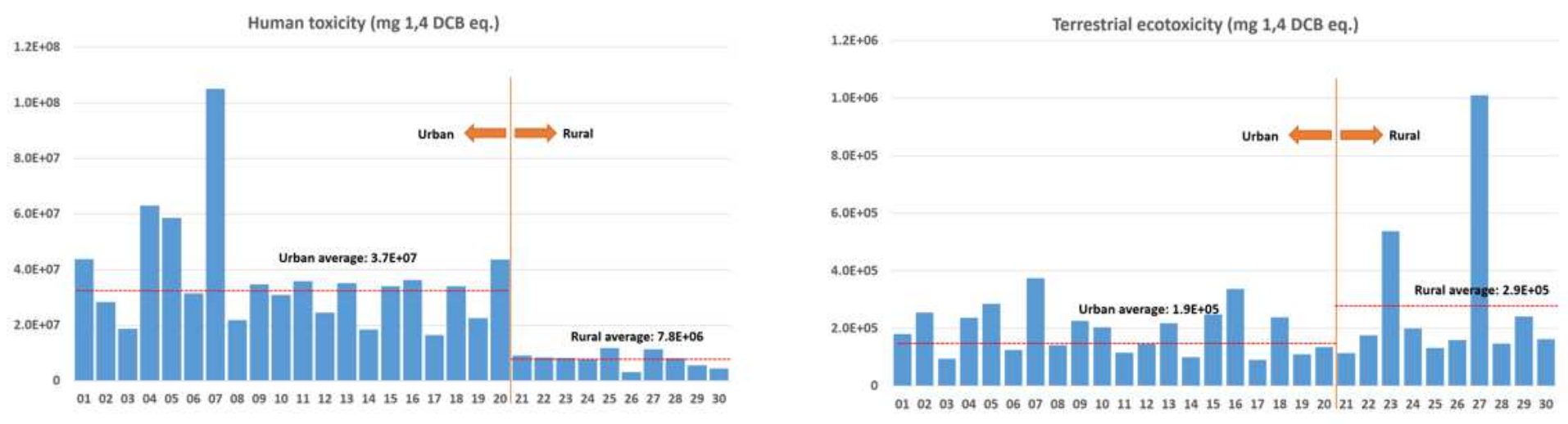

Figure 9

Human toxicity and terrestrial ecotoxicity results in urban and rural locations

\section{Supplementary Files}

This is a list of supplementary files associated with this preprint. Click to download.

- SupplMaterial1.docx

- Graphicalabstract.png 